\title{
Differential Distribution of Cell Adhesion Molecules During Histogenesis of the Chick Nervous System
}

\author{
Joanne Kelsch Daniloff, Cheng-Ming Chuong, Giovanni Levi, and Gerald M. Edelman \\ The Rockefeller University, New York, New York 10021
}

We have compared the expression of the neural cell adhesion molecule (N-CAM) and the neuron-glial cell adhesion molecule (Ng-CAM) during histogenesis of the chick nervous system. Data from immunohistochemistry and photometry were combined to construct maps of the overall distribution and dynamics of CAM appearance and disappearance. Each CAM appeared in a characteristic spatial and temporal pattern in various areas during cell movement, fiber outgrowth, tract formation, and myelination. N-CAM was more uniformly distributed than $\mathrm{Ng}-\mathrm{CAM}$ and was present on all neural cell bodies and processes of the CNS and PNS. In the adult, the staining pattern of N-CAM remained similar to that in the embryo, although the staining intensity was diminished. During embryonic development, $\mathrm{Ng}$ CAM was expressed on extending neurites and migrating neurons. The appearance of $\mathrm{Ng}-\mathrm{CAM}$ in the CNS was correlated particularly with times of cell migration in spinal cord and cerebellum, and in regions undergoing neurite extension, such as the developing white matter of the spinal cord, the optic nerve, and the medial longitudinal fasciculus. Cell bodies not undergoing migration were negative for $\mathrm{Ng}-\mathrm{CAM}$. In the adult $\mathrm{CNS}$, $\mathrm{Ng}$-CAM was markedly decreased in myelinated fiber tracts like the white matter of the spinal cord but persisted in unmyelinated regions such as the olfactory bulb. In contrast, in the PNS (for example, the dorsal root ganglion and sciatic nerve), Ng-CAM appeared early on both cell bodies and neurites, and it continued to be present on both in the adult, even in the presence of myelin. Maps comparing the relative distribution of Ng-CAM and N-CAM showed dynamic reversals as the nervous system developed and, as a result, the pattern of CAM expression was markedly different in embryos and adults. This difference appears to reflect changes in the roles of selective adhesion and of the two neuronal CAMs at different times of development.

Selective processes of neuron-neuron and neuron-glia adhesion play a fundamental role in the formation of the developing nervous system (Edelman, 1984). Calcium-independent adhesion of neurons is mediated by the neural cell adhesion molecule (N-CAM). Homophilic binding between N-CAMs on apposing cells underlies a number of developmental processes, including early cell aggregation and neurite fasciculation (Rutishauser et al., 1978; Thiery et al., 1982), the formation of complex laminar structures (Buskirk et al., 1980), nerve-muscle interactions (Grumet et al., 1982), and the formation of highly ordered retinotectal maps (Fraser et al., 1984). Definite sequences of expression of N-CAM occur during the formation of the primary developmental axis and neural plate, and later in regions where

Recivcd Apr. 22, 1985; revised June 19, 1985; accepted June 20, 1985.

We wish to thank Ms. Alison Schroeder for her excellent technical assistance. Research was supported by NIH Grants HD-09635 and AM-04256, and postdoctoral fellowships NSO7636-01 (J.K.D.) and EMBO \#ALTF 11-1984 (G.L.).

Correspondence should be addressed to Dr. Edelman, The Rockefeller University, 1230 York Avenue, New York, NY 10021.

Copyright (C) 1986 Society for Neuroscience $0270-6474 / 86 / 030739-20 \$ 02.00 / 0$ secondary inductive events occur. At each of these sites, the molecule undergoes cell surface modulation (Edelman, 1983; Edelman et al., 1983; Thiery et al., 1984). In its embryonic (E) form, N-CAM contains large amounts of polysialic acid, which diminishes in quantity, particularly during perinatal development, to yield several adult (or A) forms (Chuong and Edelman, 1984; Rothbard et al., 1982). It has been shown that $\mathrm{A}$ forms of N-CAM on synthetic vesicles mediate binding rates that are 4-5 times those of the E forms (Hoffman and Edelman, 1983). This raises the possibility that $E$ to $A$ conversion may help to stabilize neural connections (Chuong and Edelman, 1984; Edelman, 1983; Rothbard et al., 1982).

A second neuronal cell surface molecule, $\mathrm{Ng}$-CAM, first appears during embryogenesis on postmitotic neurons and has been shown to mediate the adhesion of developing neurons to glial cells (Grumet and Edelman, 1984; Grumet et al., 1984a). Unlike N-CAM, Ng-CAM appears to bind by a heterophilic mechanism (Grumet and Edelman, 1984; Grumet et al., 1984a). Although Ng-CAM and N-CAM show large differences in polypeptide and carbohydrate structure and appear to be largely unrelated molecules, they share at least one antigenic determinant (Grumet et al., 1984a, b). Highly specific and non-crossreactive antibodies to each of the two neuronal CAMs have been shown separately to inhibit brain cell aggregation, raising the possibility that the two different molecules may interact at the cell surface (Grumet et al., 1984b).

In view of the essential functions of N-CAM and Ng-CAM in neuron-neuron and neuron-glia adhesion, it is important to have detailed maps reflecting their spatiotemporal distribution in key regions of the nervous system throughout development. Such maps should reflect the dynamics of cell adhesion in developing animals, and also might reveal the potential role of these CAMs in stabilizing ncural tracts of adult animals. We report here a systematic study of the expression of the two neuronal CAMs in specific regions of the nervous system during histogenetic development. The detailed distributions of the CAMs on the spinal cord, tectum, retina, cerebellum, forebrain, and olfactory bulb were used to construct global CAM maps of the CNS and PNS. The appearances and disappearances of one or the other of the two neuronal CAMs were correlated with significant histogenetic events, including neurite extension, cell migration, tract fasciculation, and myelination.

\section{Materials and Methods}

Preparation of anti-N-CAM and anti-Ng-CAM antibodies Specific monoclonal and polyclonal antibodies to N-CAM (Hoffman et al., 1982) and to $\mathrm{Ng}$-CAM (Grumet et al., 1984a) were prepared and characterized as described.

\section{Immunoblots}

Immunoblots (Towbin et al., 1979) were performed as described previously, using polyclonal rabbit anti-Ng-CAM (Grumet et al., 1984a) 


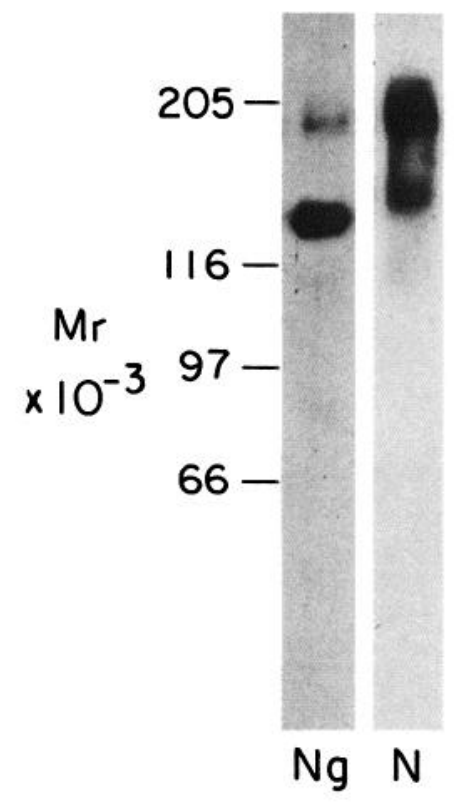

Figure 1. Immunoblots of E18 chicken tectum showing CAM antigens recognized by the antibodies used in this study. Lysates $(50 \mu \mathrm{g}$ total protein per lane) were resolved by $7.5 \%$ PAGE, transferred to nitrocellulose, and reacted with rabbit anti-Ng- and anti-N-CAM antibodies. Bound antibodies were detected by ${ }^{125} \mathrm{I}$-protein $\mathrm{A}$ binding and visualized by autoradiography. For Ng-CAM, two components were visualized, including a major band $\left(M_{\mathrm{r}}=135,000\right)$ and a minor band $\left(M_{\mathrm{r}}=200,000\right)$. For N-CAM, a mixture of embryonic form (diffuse zone from $M_{\mathrm{r}}=$ $250,000-200,000)$ and adult forms $\left(M_{\mathrm{r}}=180,000\right.$ and 140,000$)$ was seen.

or anti-N-CAM (Chuong and Edelman, 1984) antibodies to visualize the respective antigens.

\section{Immunohistology}

Tissues from white Leghorn chick embryos and adults were fixed with $2.5 \%$ paraformaldehyde- $0.02 \%$ glutaraldehyde in $0.1 \mathrm{M}$ phosphate buffer $(\mathrm{pH} \mathrm{7.0)}$ for $1 \mathrm{hr}$ at room temperature and were then washed and allowed to equilibrate overnight in $30 \%$ sucrose in phosphate buffer at $4^{\circ} \mathrm{C}$. The tissues were embedded in Lipshaw compound, frozen, and sectioned (10 $\mu \mathrm{m}$ thick) on a cryostat. After drying, adjacent sections were labeled by overnight incubation in an excess of antibodies (20-40 $\mu \mathrm{g} / \mathrm{ml}$ of $5 \%$ normal goat serum), washed, and then incubated with fluorescein-conjugated goat anti-rabbit antibodies (Miles, 1:50). In the case of monoclonal antibodies, tissue sections were incubated in rabbit anti-mouse second antibody (Miles, 1:50) prior to incubation with fluorescein-conjugated antibodies. To prevent the decay of fluorescence, a $0.1 \%$ solution of $p$-phenylenediamine dihydrochloride $(\mathrm{pH} 8.0$; Johnson and Araujo, 1981) was used in the mounting media ( $90 \%$ glycerin in PBS). Tissue sections were examined under a Zeiss epifluorescence photomicroscope.

\section{Photometry}

Quantitative measurements of relative fluorescence in stained sections were performed using a Zeiss PMI photometer with a $40 \mu \mathrm{m}$ diaphragm
(Grumet et al., 1984b). Sections were stained for N-CAM or Ng-CAM and fluorescently labeled as described above. Three or four photometric measurements from different fields in each region were taken; mean values and SDs were calculated and expressed in arbitrary dimensionless units. As an example, measurements from three separate spinal cords were used to test the variability between experiments. As a reference standard, we defined the average value found for the internal granular layer from embryonic day 18 cerebellum as 1 unit. Independent standardized values were obtained in this way for both $\mathrm{Ng}$-CAM and N-CAM. Measured values from the various ages of each region were divided by the average measured value of the cerebellar granular layer that was obtained in the same experiment.

\section{Results}

The distribution of $\mathrm{Ng}$-CAM, which was found predominantly on neurites (Thiery et al., 1985) and migrating neurons (Grumet et al., 1984b) was compared with that of N-CAM, which was ubiquitous on cell bodies and neurites. The two CAMs were localized by immunohistochemistry in adjacent frozen sections in the spinal cord and dorsal root ganglion (DRG), as well as in cerebellum, optic tectum, retina, forebrain, olfactory bulb, and sciatic nerve. In describing the results, developing fibrous tracts or funiculi will be referred to as prospective white matter, and groups or columns of neurons as prospective gray matter, regardless of their lack of myelination or final formation into discrete groups at the time of description.

Monoclonal and polyclonal antibodies used in these studies recognized the major polypeptide components of chicken $\mathrm{Ng}$ CAM $\left(M_{r}=200,000,135,000\right.$; Grumet and Edelman, 1984) and both E and A forms of N-CAM $\left(M_{\mathrm{r}}=250,000-180,000\right.$, and 140,000; Rothbard et al., 1982), as detected by a Western blot of tissue lysates from embryonic day 18 tectum (Fig. 1). In control experiments for specificity of staining, these anti-CAM antibodies were found to be neutralized by prior incubation with immunoaffinity-purified Ng-CAM and N-CAM.

\section{Immunohistochemical localization \\ Spinal cord}

Well-studied temporal sequences of cell migration and the formation of discrete funiculi occur in the developing spinal cord (Altman and Bayer, 1984). The appearance of CAMs in these areas was coincident with these key developmental events (Figs. 2 and 3 ), and indicated that, while N-CAM is more widely distributed on neurons (compare Fig. 2, B, D, F, and $H$ ), NgCAM is specifically localized and dynamically changes on cell bodies and neurites during their movement (compare Fig. 2, A, $C, E$, and $G$ ). The central canal, the vestigial lumen of the neural tube, was lined with ependymal cells that were positive for $\mathrm{N}-\mathrm{CAM}$ but negative for $\mathrm{Ng}-\mathrm{CAM}$.

On embryonic day 5 (E5), the ventral funiculus (VF in Fig. $2 A$ ) was stained brightly with anti- $\mathrm{Ng}$-CAM antibodies, consistent with its appearance on E3 and continued development at E5 (Hamburger, 1948). This funiculus is formed by fibers from the dorsal horn, which converge on the ventral root and eventually grow toward developing myotomes (Altman and Bayer, 1984). The dorsal funiculus (oval bundle of His), containing

Figure 2. Expression of Ng-CAM and N-CAM in midcervical spinal cord. Transverse sections were stained with rabbit anti-Ng-CAM IgG $(A$, $C$, $E, G)$, and adjacent sections stained with rabbit anti-N-CAM $\operatorname{IgG}(B, D, F, H)$. A, At E5, Ng-CAM was localized within the ventral commissure $(V C)$, the ventral funiculus $(V F)$, and dorsal funiculus $(D F)$, and on migrating neurons within the developing ventral horn $(V H)$. Neuroepithelial cells $(N E)$ were not stained. $B$, At E5, anti-N-CAM antibodies recognized all neural cells and fibers. $C$, At E8, anti-Ng-CAM stained the dorsal funiculus more intensely than the ventral funiculus. Neuroepithelial cells were not stained. $D$, At E8, all neurons and processes, including the neuroepithelial cells, were stained by anti-N-CAM antibodies. $E$, At E18, intense Ng-CAM staining within a semicircular pathway of fibers (FM, fibers of the marginal nucleus), presumably originating within the marginal zone and coursing around the developing horn. The neuroepithelial cells and parts of the lateral (small arrow) and ventral funiculi were unlabeled. $F$, At E18, anti-N-CAM stained all neurons and fibers, including those regions (small arrow) not stained with anti-Ng-CAM. The semicircular fibers were also prominent. $G$, Adult stage, left half of the spinal cord. The central gray matter and marginal (Hofmann's minor) nucleus of the lateral funiculus (small arrow) were brightly stained with $\mathrm{Ng}$-CAM. $H$, Adult stage, left half of spinal cord. The gray matter and marginal nucleus (small arrow) were more intensely labeled with anti-N-CAM than fibers in the white matter. $A-D, \times 52 ; E, F, \times 45 ; G, H, \times 22$. 

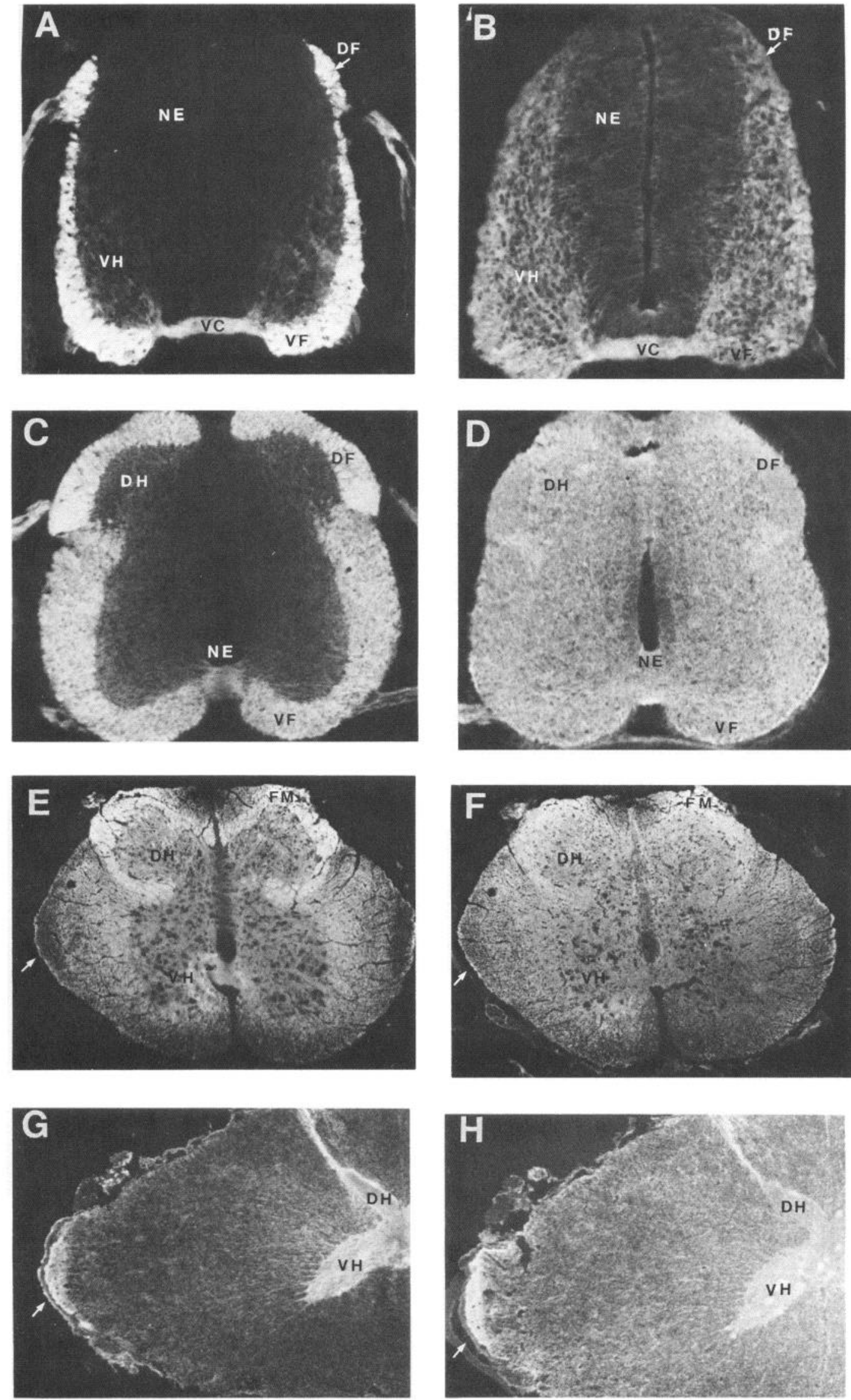

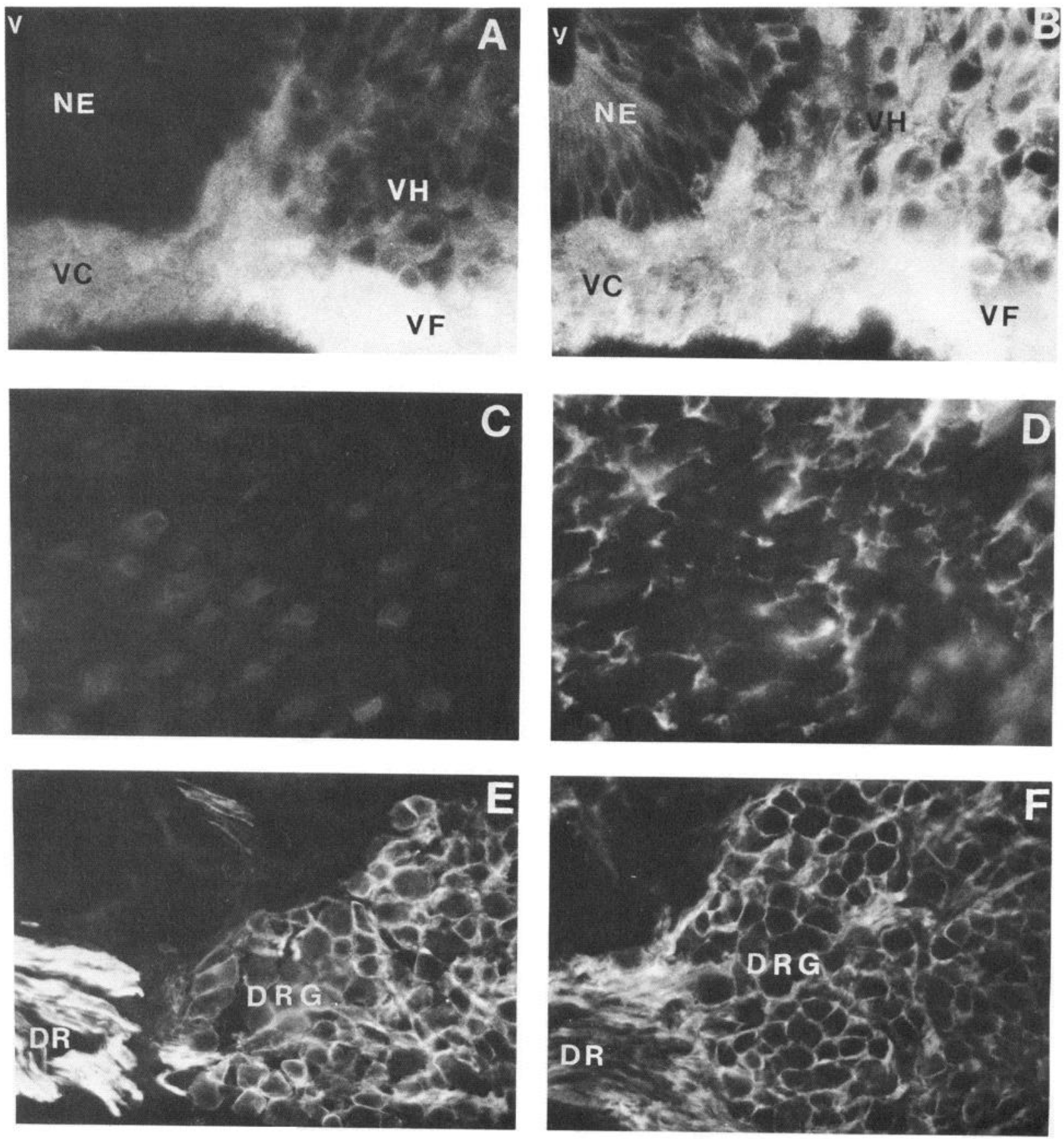

Figure 3. Spinal cord and dorsal root ganglia (DRG), higher magnification. Transverse sections stained with polyclonal anti-Ng-CAM IgG $(A, C$, $E$ ), and adjacent sections with anti-N-CAM $\operatorname{IgG}(B, D, F)$. A, E5: Ventral aspect of spinal cord (see Fig. $2 A)$, where ventral commissure $(V C)$ and funiculus $(V F)$ and migrating neurons within the ventral horn $(V H)$ were stained for $\mathrm{Ng}$-CAM. Neuroepithelial cells $(N E)$ lining the ventricle $(V)$ were not stained. B, E5: Anti-N-CAM antibodies labeled all cells and fibers, including the neuroepithelial cells lining the ventricle. $C$, Adult: Fiber bundles in the lateral white funiculus were faintly labeled with anti-Ng-CAM. $D$, Adult: All cell bodies and processes were positive for N-CAM, including the $\mathrm{Ng}$-CAM positive fiber bundles. E, E5: $D R G$ stained with anti-Ng-CAM. The cell bodies, dorsal roots $(D R)$, and ventral roots (not shown) were labeled. $F$, E5: Anti-N-CAM antibodies labeled the same structures. An identical staining pattern was observed for both reagents in
this tissue during development. $A, B, \times 300 ; C, D, \times 500 ; E, F, \times 100$.

fibers from the DRG (Altman and Bayer, 1984) also stained brightly. Staining by anti-Ng-CAM was also intense in fibers of the ventral commissure (VC in Figs. $2 A$ and $3 A$ ), which begin to extend ipsilaterally on E3 (Hamburger, 1948) and are prominent on E4 (Ramon y Cajal, 1960). Both the cell bodies and roots of the DRG were stained for $\mathrm{Ng}-\mathrm{CAM}$ at this age, even though these cell bodies are no longer moving at this time (Hamburger, 1948). Neuroepithelial cells were not stained (Fig. $3 A$ ). By E8, both the dorsal and ventral funiculi had increased sub- stantially in size, as reflected in the $\mathrm{Ng}$-CAM staining pattern in Figure $2 C$. The dorsal funiculus was more brightly stained than the ventral funiculus, especially in the region adjacent to incoming afferents from the DRG. Within the developing ventral horn, labeled cell bodies were not observed, coincident with the cessation of migration (Hamburger, 1948). Neuronal cell bodies were labeled in the developing dorsal column (not shown); this may reflect the movement of cells into this column that occurs between E5 and E8 (Hamburger, 1948). DRG cells and 

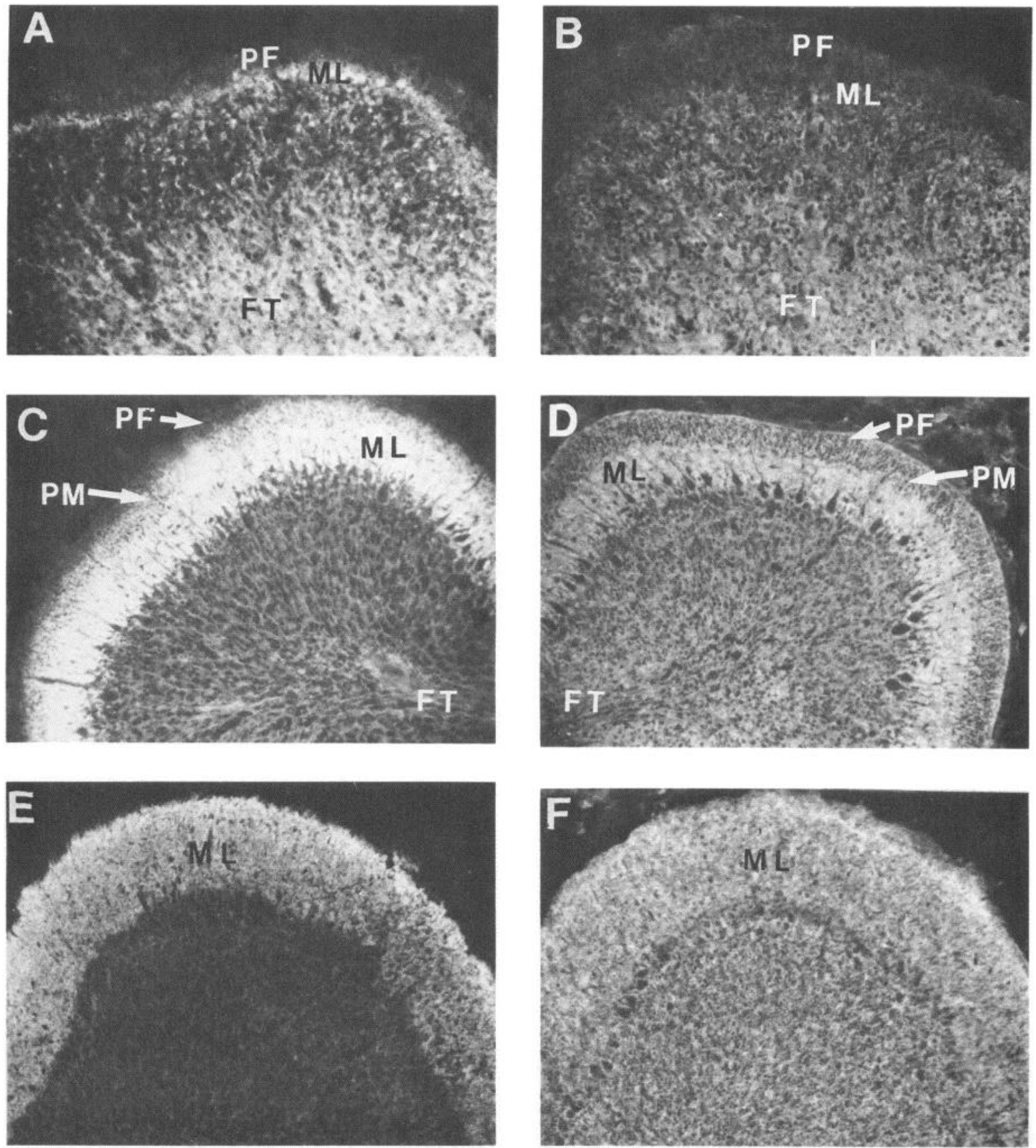

Figure 4. Distribution of anti-Ng-CAM $(A, C, E)$ and anti-N-CAM IgG $(B, D, F)$ immunofluorescence in cerebellum. $A$, E12: Processes were labeled within the narrow molecular layer $(M L)$ and fibrous tract $(F T)$, and the proliferative zone $(P F)$ was not stained. $B$, E12: All neuronal elements were visualized with anti-N-CAM IgG, although the fibrous tracts were brighter than the molecular layer. $C$, E18: Granule cells were not stained in the proliferative zone $(P F)$. Premigratory granule cells $(P M)$ and the molecular layer $(M L)$ were brightly stained with anti-Ng-CAM. $D$, E18: All neuronal elements were labeled with anti-N-CAM antibodies, including both proliferating and migrating cell bodies. $E$, Adult: The molecular layer $(M L)$ retained a diminished $\mathrm{Ng}$-CAM label, and only faint staining was observed in the fibrous tract. No cell bodies were stained. $F$, Adult: The fibrous tract and molecular layer were slightly brighter than the other regions, but all cell bodies and processes were stained. $A-D$, $\times 150 ; E, F, \times 100$.

fibers were labeled and the neuroepithelial cells remained unstained.

At E18, the Ng-CAM staining pattern of the developing gray regions versus funiculi was no longer as distinct as it was earlier (Fig. $2 E$ ). The intensity began to increase within the developing dorsal and ventral horns, which correlates with the time when large numbers of collaterals from the funiculi grow into these horns (Hamburger, 1948). Portions of the lateral and ventral funiculi were devoid of $\mathrm{Ng}-\mathrm{CAM}$ staining (small arrow in Fig.
$2 E$ ). A fibrous ring of brightly labeled $\mathrm{Ng}$-CAM-bearing fibers encircled the perimeter of the dorsal horn; this may be the semicircular pathway that originates within the marginal zone of the gray matter and becomes part of the spinothalamic tract (Trevino et al., 1972). The neuroepithelial cells remained devoid of Ng-CAM label, while the DRG fibers and cells remained $\mathrm{Ng}$ CAM positive.

In the adult spinal cord, the $\mathrm{Ng}-\mathrm{CAM}$ staining pattern reversed as compared to E8 spinal cord (Fig. 2, $C$ and $G$ ). The 

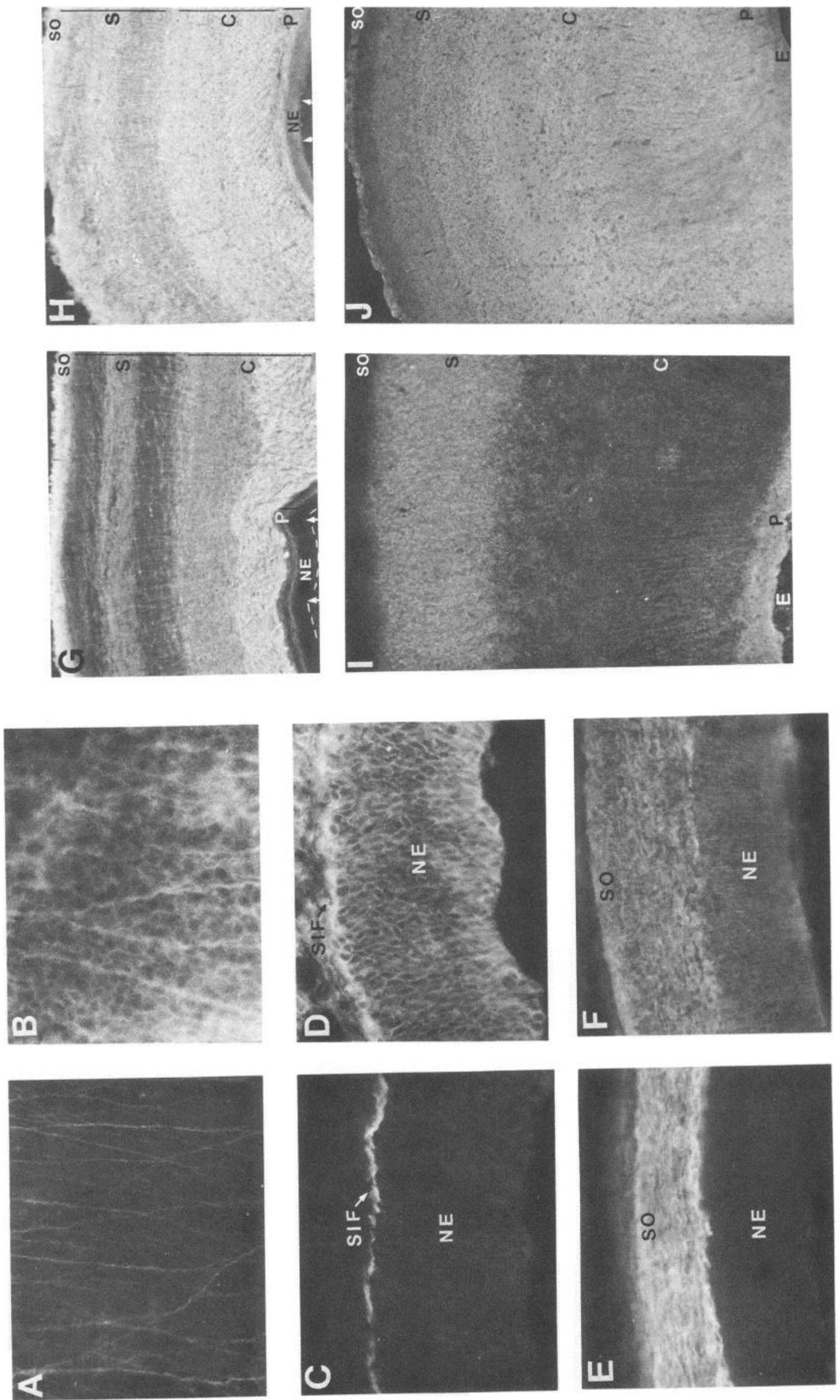
gray matter, which includes the peripherally located marginal nuclei of Hofmann (Dubey et al., 1968; Van den Akker, 1970; small arrow in Fig. $2 G$ ) exhibited significantly greater intensity of staining for $\mathrm{Ng}$-CAM than did the white matter. Fibers within these regions are unmyelinated and expressed $\mathrm{Ng}$-CAM, but the molecule was not present on cell bodies.

N-CAM was more ubiquitously distributed at all ages than $\mathrm{Ng}$-CAM (for example, compare Fig. 2, $A$ and $B, C$ and $D$ ). At E5, the cells of the developing ventral horn, the fibers of the ventral commissure, the dorsal and ventral funiculi, as well as fibers and neurons of the DRG were all stained by anti-N-CAM with similar intensities. In contrast to the findings with anti$\mathrm{Ng}$-CAM, neuroepithelial cells stained positively for N-CAM. This is seen in Figure $2, A$ and $B$, with details illustrated in Figure $3, A$ and $B$, where the ventromedial aspect of the developing spinal cord is shown at higher magnification. At F8 (Fig. 2D), E18 (Fig. $2 F$ ), and in the adult (Fig. $2 H$ ), all fibers and cell bodies, including those within the DRG and neuroepithelium, were labeled with anti-N-CAM antibodies. In Figure $2 F$, the semicircular "cap" of the dorsal horn was stained more brightly than the surrounding tissue. In addition, the gray matter of the adult was more intensely stained with anti-N-CAM than previously (compare Fig. 2, $F$ and $H$ ), although the differences in staining intensities between gray and white matter were less obvious for N-CAM as compared with Ng-CAM.

Several regions of interest are shown at higher magnification in Figure 3. In the developing ventral horn (E5), cell bodies were labeled with $\mathrm{Ng}$-CAM during their migratory phase (Hamburger, 1948). In the adult lateral funiculus, $\mathrm{Ng}$-CAM labeling was observed on what appeared to be distinct fiber bundles (Fig. $3 C$ ), while all fiber bundles and neurons were labeled for N-CAM (Fig. 3D). The distribution of CAMs in the adult DRG (not shown) was the same as that seen during development (E5; Fig. $3, E$ and $F$ ).

\section{Cerebellum}

The cerebellum is derived from thickenings of the rhombic lip and consists of a gray cortical zone and a medullary core of fibrous tracts. There is well-documented "outside-in" passage of the granule cells that migrate from the external granule layer through the molecular layer to their destination in the inner granule layer (Rakic, 1971). The established times of granule cell migration and tract formation were found to be correlated with the staining patterns of the two CAMs.

On E12, Ng-CAM was localized within a narrow molecular layer and in the fiber tracts (prospective white matter, Fig. $4 A$ ). Around E18, the external granule layer is divided into the proliferative (PF in Fig. 4) and premigratory (PM in Fig. 4) zones (Altman, 1972; Rakic, 1971). At E18, granule cell bodies within the proliferative zone did not express $\mathrm{Ng}$-CAM, but those in the premigratory zone (Fig. $4 \mathrm{C}$ ) were $\mathrm{Ng}-\mathrm{CAM}$ positive at $\mathrm{E} 18$ (Grumet et al., 1984b). At this time, the granule cells are migrating through the molecular layer (ML in Fig. 4) on their way to the inner granular layer, and the number of fibers in this region increases considerably. Both factors may contribute to the peak intensity of the $\mathrm{Ng}-\mathrm{CAM}$ label in the molecular layer at E18. The fiber tracts ( $\mathrm{Fl}$ in Fig. 4), containing afferent and efferent fibers, were also positively labeled. In the adult (Fig. $4 E$ ), fibers within the molecular layer expressed $\mathrm{Ng}$-CAM, but the intensity of fluorescence was diminished relative to that of E18 (compare Fig. 4, $C$ and $E$ ).

N-CAM was more evenly distributed throughout the developing and adult cerebellum. On E12, staining was most intense within the fiber tracts (Fig. $4 B$ ). At E18 (Fig. $4 D$ ) and in the adult (Fig. $4 F$ ), all layers of cerebellum were N-CAM positive. In the adult, the molecular layer showed the most intense staining.

\section{Optic tectum}

The avian optic tectum, the primary termination of the optic tract, develops from two longitudinal eminences of the mesencephalon (Huber and Crosby, 1933). The laminae of the mature tectum are formed by waves of migrating neuroblasts that follow an "inside-out" sequence of development (LaVail and Cowan, 1971). We adopted the terminology suggested by Huber and Crosby (1933) to describe the six fundamental tectal laminae (refer to Fig. 5, $G$ and $H$ ). The stratum opticum (SO) contains the incoming optic fibers that are received by the stratum griseum et fibrosum superficiale (SGFS; $S$ in Fig. 5). Neurons within the stratum griseum centrale (SGC) send their axons through the stratum album centrale (SAC) to form the major efferent pathways (e.g., tectubulbar tract) of the tectum (C in Fig. 5). Finally, of the deepest laminae, stratum griseum periventriculare (SGP) sends axonal processes to the SAC, and dendrites towards the ventricle, and the fibers of stratum fibrosum periventriculare (SFP; $P$ in Fig. 5) circumscribe the ventricle and receive fascicles from the hypothalamus, inferior colliculus, and cerebellum (Jungherr, 1945). All sections in the coronal plane were from middle regions of the developing tectum. The distribution of CAMs showed heterogenous and dynamic shifts of pattern during the development of these laminae.

Early on E4, in whole-mount preparations, a sparse layer of brightly Ng-CAM positive fibers coursed obliquely across the apical surface of $\mathrm{Ng}-\mathrm{CAM}$ negative cells (Fig. $5 \mathrm{~A}$ ). Such surface fibers on the tectum have been described previously (LaVail and Cowan, 1971), and may be the origin of the developing tectobulbar tract (Goldbcrg, 1974). At higher magnification (not shown), these fibers seemed to originate from the first group of differentiated tectal cells (LaVail and Cowan, 1971). In later stages, incoming optic fibers grew on top of this fiber layer and formed the SO. By E5, the number of fibers had increased and fascicles were formed (Fig. $5 \mathrm{C}$ ). No other $\mathrm{Ng}$-CAM positive elements were apparent within the tectum at this stage. From E6 to E12, Ng-CAM positive axons from retinal ganglion cells spread across the tectal surface to form the SO (DeLong and Coulombre, 1965; Goldberg, 1974); and on E8, these fibers turn

Figure 5. Whole-mount preparations, from midtectum, of the superficial tectal surface with meninges removed $(A, B)$ and adjacent coronal sections $(C-J) . A, \mathrm{E} 4: \mathrm{Ng}$-CAM positive fibers coursed obliquely across the tectal surface, presumably originating from the first wave of differentiated neurons. $B$, E4: Both the superficial fibers and the cell bodies beneath them were stained with N-CAM. $C$, E5: An increased number of superficial fibcrs $(S I F)$ were stained with anti-Ng-CAM antibodies, but neuroepithelial cells $(N E)$ were unlabeled. $D$, E5: All fibers and cells were visualized with anti-N-CAM antibodies. $E$, E8: The $S O$, containing retinal afferents, was intensely stained for Ng-CAM, while the neuroepithelial cells remained unlabeled. F, E8: Anti-N-CAM antibodies visualized both the neuroepithelium and SO, but the staining on fibers was brighter. $G$, E12: Distribution of $\mathrm{Ng}$-CAM began to show a substantial increase in laminar complexity. From the tectal surface toward the ventricle, the SO was the brightest layer, and three regions within the developing SGFS $(S)$ were observed just beneath it. Deeper, the large SGC and SAC constituted the developing central $(C)$ regions of the tectum. The SGP and a thin layer of radially oriented fibers (the developing SFP) constituted the periventricular zone $(P)$; all these laminae were superficial to the unlabeled neuroepithelial cells. $H$, E12: The staining pattern for N-CAM was much more homogeneous than Ng-CAM's. At this magnification, three zones of the SGFS were distinguishable from the other laminae. Neuroepithelial cells were also N-CAM positive. I, Adult: The SO was no longer labeled with anti-Ng-CAM antibodies, but fibers within SGFS were still positive. The SAC was weakly labeled, and all cell bodies, including ependyma, were negative. $J$, Adult: The adult tectum was homogeneously stained for N-CAM except for a fiber-free zone in the SGFS. $A, B, \times 280 ; C, D, \times 250 ; E, F, \times 100 ; G-J, \times 43$. 

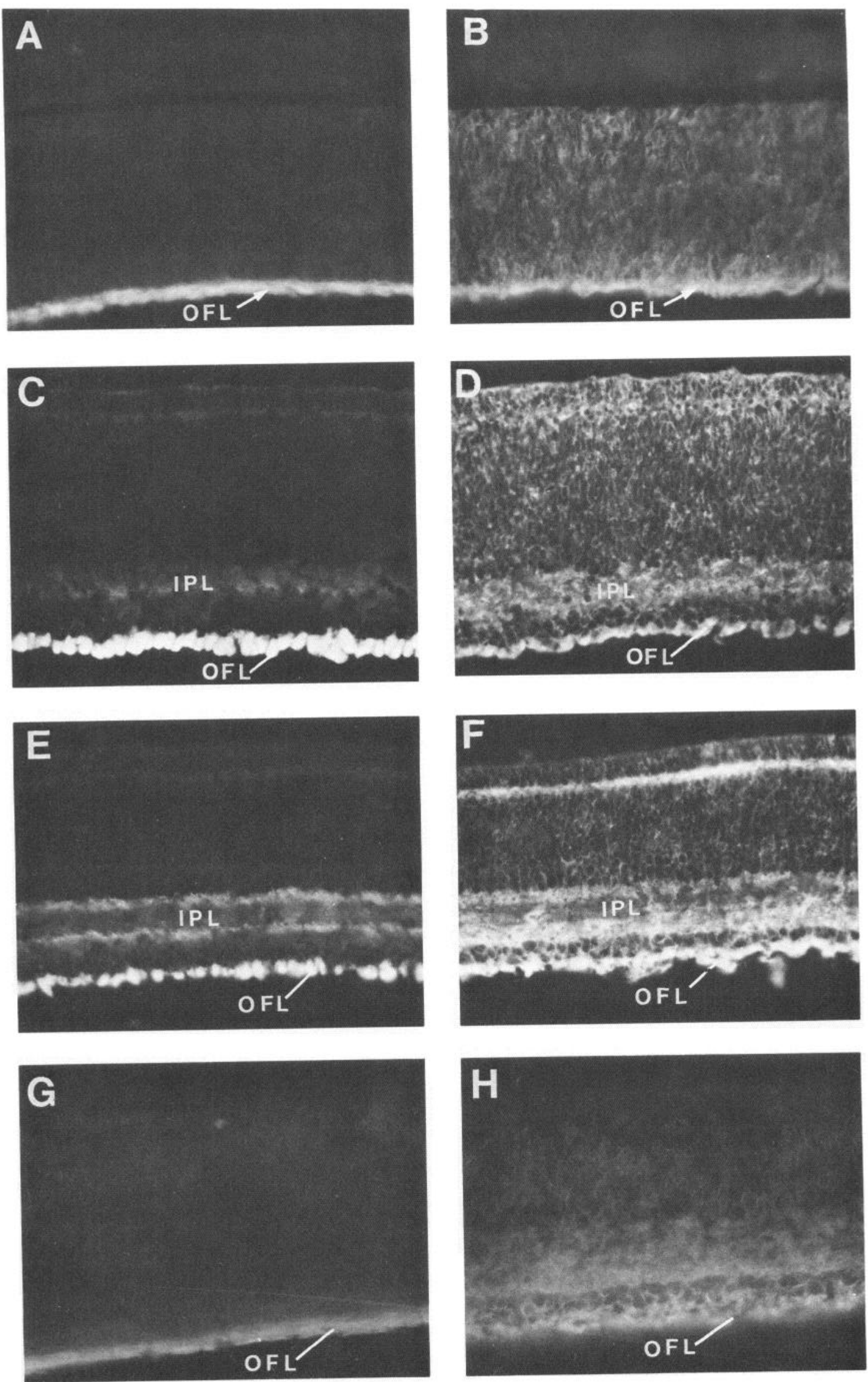
downward and invade the SGFS (Rager and von Oeynhausen, 1979). On E8 (Fig. 5E), the developing SO was brightly stained with anti-Ng-CAM.

The $\mathrm{Ng}-\mathrm{CAM}$ staining pattern also reflected the known increase in laminar complexity that occurs with development (Fig. $5 G$ ). On E12, the peripheral SO, which does not become myelinated until E16-E18 (Rager, 1977), was the most intensely stained layer (Fig. $5 G$ ). In the adult, the most conspicuous characteristic (Fig. $5 I$ ) was the absence of $\mathrm{Ng}$-CAM staining within the $\mathrm{SO}$, which was heavily myelinated (Rager, 1977). On E12, the three layers immediately beneath SO (S in Fig. 5, $G$ and $H$ ) constitute the developing SGFS. There was a sparsely stained region of cell bodies and two regions of labeled fibers; one ran parallel and one ran perpendicular to the surface. Two thick layers deep to the SGFS become the central region (C in Fig. 5, $G$ and $H$ ). Within the SGC, which contained labeled fibers and unstained cell bodies, we could not distinguish whether the antibodies to $\mathrm{Ng}$-CAM labeled dendrites or axons. Deep to the SGC was a wide region representing the differentiating $\mathrm{SAC}$, which was dominated by brightly stained fibers and showed occasional, unlabeled cell bodies. The periventricular zone (P in Fig. 5, $G$ and $H$ ) was distinguished from the other zones and contained a narrow region of unstained cell bodies (the developing SGP), and a thin layer of radially oriented $\mathrm{Ng}$-CAM positive fibers (the SFP). The neuroepithelial cells were $\mathrm{Ng}$-CAM negative. Fibers within the adult SGFS retained some N-CAM staining, but SAC was devoid of Ng-CAM (Fig. 5I). Anti-Ng-CAM antibodies labeled radially oriented fibers within the SGC (not shown); a prominent band was stained within the SFP, and the SGP neurons were negative. Ependymal cells were unlabeled in the adult.

At all stages of tectal development, the patterns of N-CAM staining differed from those of $\mathrm{Ng}$-CAM staining. In wholemount tectal preparations at E4 (Fig. 5B), anti-N-CAM antibodies stained both the superficial fiber layer and the cell bodies immediately deep to it. Between E4 and E5 (Fig. 5D), N-CAM was expressed by both neuroblasts and fibers, although the greatest staining intensity was found within the superficial fiber bundle. On E8, laminae began to develop (Fig. $5 F$ ); the neuroepithelial zone was easily distinguished from the more superficial layers. By E12, N-CAM was more homogeneously distributed than Ng-CAM, and it was more difficult to distinguish anti-NCAM stained tectal laminae than those stained by anti-Ng-CAM (compare Fig. 5, $G$ and $H$ ). Although three subregions within the developing SGFS were observed, the distinction between SAC and SCG was not obvious. The two periventricular zones and the ependymal lining of the ventricle were all labeled distinctly. In the adult, all fibers and cell bodies were labeled, but two layers (SGFS, within the region labeled " $S$ " in Figure $5 J$, and SFP within periventricular or $\mathrm{P}$ zone) were brighter than the others. In contrast to $\mathrm{Ng}-\mathrm{CAM}, \mathrm{N}-\mathrm{CAM}$ was expressed in SO of the adult (compare Fig. 5, $I$ and $J$ ).

\section{Retina}

The retina develops from the optic cup. Distributions of CAMs were mapped onto the important developmental sequences, including the elaboration of neurites to form a complex laminar structure and the outgrowth of axons from ganglion cells to form the optic nerve.

On E5, Ng-CAM was localized exclusively on the axonal processes of the optic fiber layer (OFL), and this pattern was retained throughout embryonic development. The ganglion cell bodies, which are generated as early as E2 (Rager, 1977), were not stained with Ng-CAM (Fig. 6A). By E12, fibers within the inner plexiform layer (IPL), which contains dendrites from ganglion and amacrine cells (Kager and Rager, 1978) and which begins to mature on E8 (Rager, 1977), were weakly stained for Ng-CAM. Labeled cell bodies were not observed, although ganglion cells migrate through this layer until E12 (Rager, 1977). Tangential layers within the IPL (Fig. $6 E$ ), which are formed by uni- or multistratified dendrites of the ganglion and amacrine cells (Rager, 1977), were visualized with anti-Ng-CAM antibodies by E18. The outer plexiform layer (OPL), which is just beginning to form at E12 (Rager and Rager, 1978), stained weakly for $\mathrm{Ng}$-CAM on both E12 (Fig. 6C) and E18 (Fig. 6E). The OFL was weakly labeled (Fig. $6 G$ ), but the remaining regions of the retina were devoid of fluorescent label.

Anti-N-CAM antibodies labeled all of the developing retinal layers (Fig. 6, $B, D$, and $F$; see also Buskirk et al., 1980), although the OFL was the brightest and the IPL was clearly distinguishable from adjacent layers. By.E18, fibers within the OPL were also brightly stained by anti-N-CAM (Fig. $6 F$ ). All layers of the adult retina were labeled with anti-N-CAM, and the OFL remained the most intensely stained (Fig. $6 H$ ).

Figure 7 summarizes the typical CAM distributions in the adult for retina and optic nerve $(A, C)$ and for the superficial layers of the tectum $(B, D)$. The entire pathway was labeled with anti-N-CAM antibodies, including the ganglion cell bodies, OFL, and optic nerve (Fig. 7A), and the SGFS was brighter than the SO (Fig. $7 B$ ). In contrast, only the OFL and the proximal segment of the optic stalk were labeled with anti-Ng-CAM antibodies (Fig. 7C). As indicated above, during development, the optic fibers and SO expressed Ng-CAM. The tract acquires its myelin sheath after it passes the lamina cribosa of the sclera (Williams and Warwick, 1980), and it was at this point that the optic nerve was no longer $\mathrm{Ng}-\mathrm{CAM}$ positive. The $\mathrm{SO}$ was also unlabeled (Fig. 7D), but within the SGFS, where axons of the $\mathrm{SO}$ terminate, fibers were positive for $\mathrm{Ng}$-CAM. At this level of resolution it could not be determined whether Ng-CAM is present on ganglion fibers or dendrites of SGFS.

\section{Forebrain}

The forebrain, including the telencephalon and diencephalon, develops from two evaginating vesicles (Williams and Warwick, 1980). This study revealed that $\mathrm{Ng}$-CAM labeled the fiber tracts as they developed, but the same fibers were not labcled in the adult.

The distribution of $\mathrm{Ng}$-CAM within the sagittal plane of the developing chick brain on E9 is illustrated in Figure $8 A$. Developing fiber tracts, including the olfactory (Ol.T in Fig. 8) and optic tracts (OT in Fig. 8) of the forebrain were discretely labeled, as were the medial longitudinal fasciculus (MLF) and the tectobulbar (TB) and tectothalamic (TT) tracts of the brain stem (see Fig. 8; Kuhlenbeck, 1937; Windle and Austin, 1935). A

\footnotetext{
Figure 6. Immunofluorescence labeling of transverse retinal sections with polyclonal anti-Ng-CAM $(A, C, E, C)$ and anti-N-CAM IgG $(B, D, F$, $H$ ). A, E5: The axons of the optic fiber layer $(O F L)$ were visualized with anti-Ng-CAM. B, E5: All layers were N-CAM positive. $C$, E12: The OFL was brightly stained for $\mathrm{Ng}$-CAM, and the developing internal plexiform layer $(I P L)$ was weakly labeled. $D$, E12: All fibers and cell bodies were visualized by anti-N-CAM antibodies, but the OFL, IPL, and developing external plexiform layer were brighter than the other layers. $E$, E18: The OFL was brightly stained with anti-Ng-CAM antibodies, and tangential (dendritic) layers within the IPL were brightly stained. No cell bodies were labeled. F, E18: All neuronal elements were stained for N-CAM, but the internal and external plexiform layers were more intense than other layers. $G$, Adult: The OFL retained its $\mathrm{Ng}$-CAM label, although the intensity decreased. $H$, Adult: Anti-N-CAM antibodies stained all neuronal cell bodies and processes, but weakly. $A-F, \times 220 ; G, H, \times 200$.
} 

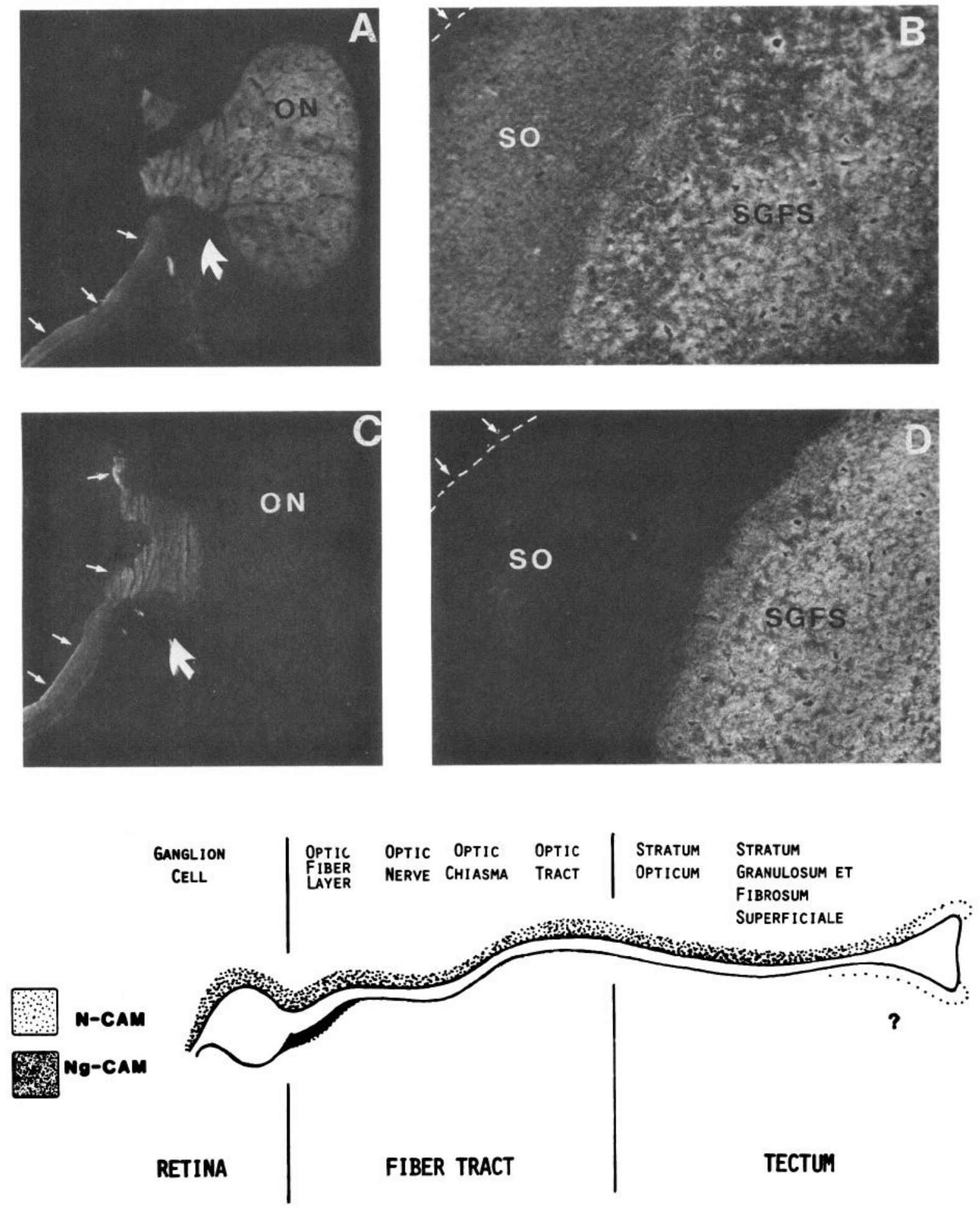

Figure 7. Adult retinotectal projection in photomicrographs $(A-D)$ and schematic summary. Oblique section through retina and attached optic nerve $(A, C)$ and transverse sections of superficial layers of ventral tectum $(B, D)$. $A$, The retina (small arrows) and optic nerve $(O N)$ stained positively with anti-N-CAM antibodies. $B$, The N-CAM label was retained within the $S O$ and the $S G F S$ of the tectum. $C$, Anti-Ng-CAM antibodies stained the retinal OFL within the sclera, but the staining decreased sharply after the optic nerve exited the orbit (large arrow). $D$, Ng-CAM staining was not observed on the SO, but the SGFS was labeled. Below, Schematic representation indicates that N-CAM (upper half of the ganglion cell) was expressed homogeneously in the adult, while $\mathrm{Ng}$-CAM was restricted to within the orbit (lower half of the ganglion cell). The question mark indicates our uncertainty about the localization of Ng-CAM within the SGFS, where either the termination of the ganglion cells or intrinsic dendrites could have been labeled. $A, C, \times 35 ; B, D, \times 100$.

portion of the adult MLF stained with anti-Ng-CAM, located within the rectangular area indicated in Figure $8 A$, is shown in Figure $8 B$. Most of the fascicles within this tract were no longer stained, but the neuropil between the bundles was definitely labeled.
As in other areas, the N-CAM distribution (Fig. $8 \mathrm{C}$ ) was more homogeneous than that of $\mathrm{Ng}-\mathrm{CAM}$, and tracts were not as well delineated. Within the adult MLF (Fig. $8 D$ ), all fibers were $\mathrm{N}-\mathrm{CAM}$ positive, and staining of the fiber bundles was less intense than that of the surrounding tissues. 

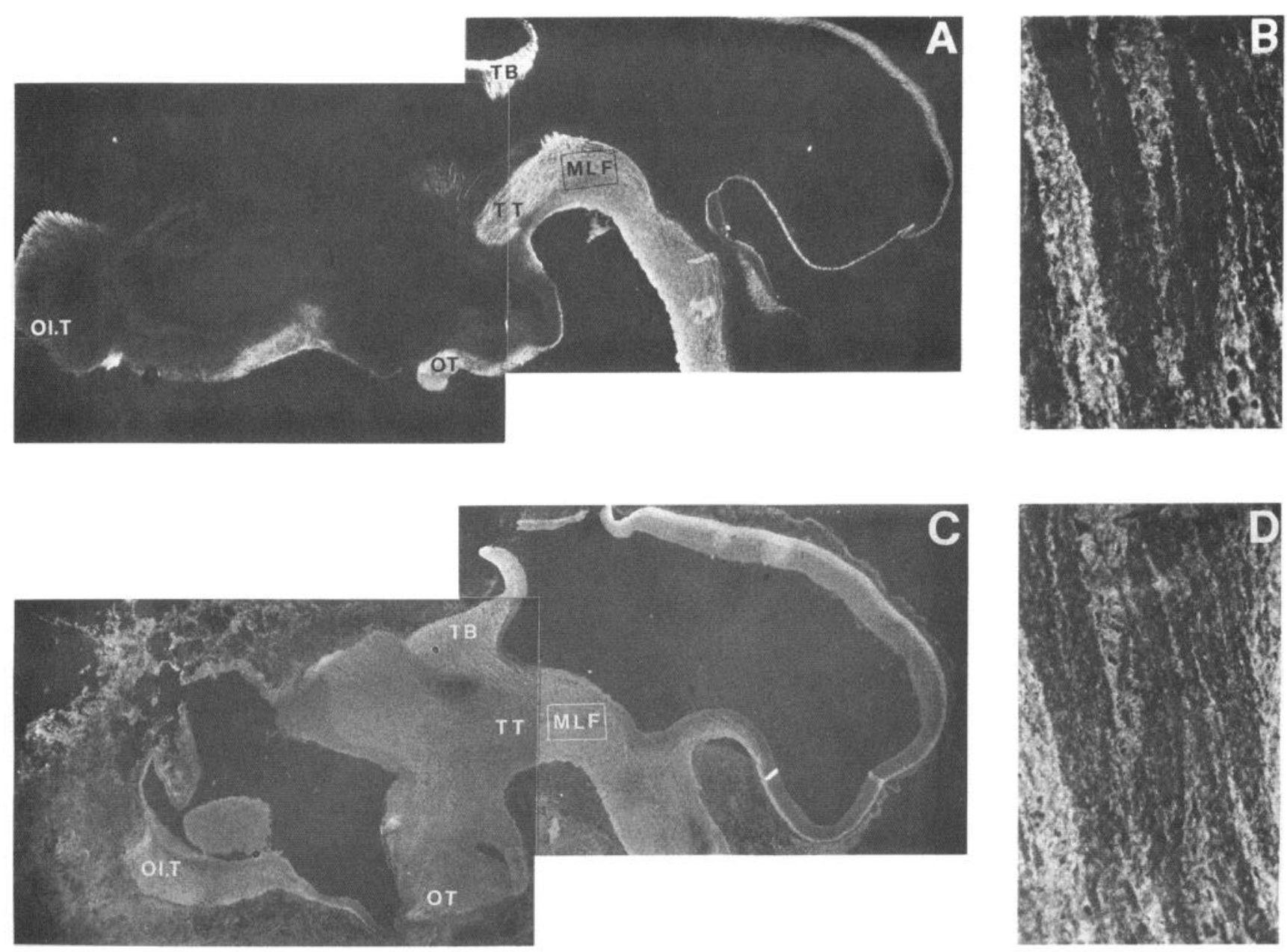

Figure 8. Parasagittal sections of embryonic $(A, C)$ and adult $(B, D)$ brains. $A$, E9: Ng-CAM stained specific developing pathways including the olfactory tract $(O l . T)$, optic tract $(O T)$, medial longitudinal fasciculus $(M L F)$, tectobulbar tract $(T B)$, and tectothalamic tract $(T T)$. B, Adult: Portion of the MLF taken from the corresponding area in $A$, at higher magnification. The myelinated MLF fiber bundles were devoid of fluorescence label, and the regions between the bundles were faintly labeled. $C$, E9: In this section slightly medial to $A$, N-CAM was distributed throughout the embryo; the tectum and tectobulbar tract were more intensely labeled than surrounding regions. $D$, Adult: Most of the MLF fibers (corresponding to the window marked in $C$ ) were positively stained for N-CAM. The neuropil between the myelinated bundles was more intensely stained than the corresponding regions stained for Ng-CAM. $A, C, \times 13 ; B, D, \times 175$.

\section{Olfactory bulb}

The olfactory bulb differentiates from the basal surface of the forebrain (Williams and Warwick, 1980). Olfactory receptor cells project to the bulb via unmyelinated olfactory nerves, and there is evidence in mammals of a persistence of neurogenesis within olfactory mucosa (Graziadei and Graziadei, 1977). This region was of particular interest because previous studies (Chuong and Edelman, 1984) have revealed a high amount of the E form of N-CAM in this region. The distributions found in the present study demonstrated that nonmyelinated adult fibers continue to express both Ng-CAM and N-CAM molecules.

In the olfactory bulb, the general staining pattern did not change during maturation (not shown), although the relative intensity of both CAM labels was slightly diminished in adult tissue (Fig. 9, $A$ and $B$ ). In this respect, the olfactory system was unique. $\mathrm{Ng}-\mathrm{CAM}$ was localized along the periphery (Gl. in Fig. $9 A$ ), which contains the glomeruli formed by the nonmyelinated olfactory nerves and the dendrites of mitral cells. The middle gray zone (EPL), which contains the mitral cells and granule cells and their dendrites, was labeled faintly by anti-Ng-CAM. In contrast, fibers within the olfactory tract (Ol.T) were brightly stained. Antibodies to N-CAM stained the glomerular region more intensely than surrounding regions, but the gray matter was indistinguishable from the olfactory tract (Fig. 9B).

\section{Sciatic nerve}

During development, both Ng-CAM and N-CAM were localized on the surface of axons in the sciatic nerve (not shown). In the adult (Fig. 9, $C$ and $D$ ), the staining pattern remained the same, although as expected, the number of fibers within the nerve was increased.

\section{Quantitation of antigens}

Various brain regions were measured by photometry to confirm the visual estimates of fluorescence made on tissue sections. The photometric analyses of four sampled brain regions are summarized in Table 1 . The expression of $\mathrm{Ng}-\mathrm{CAM}$ can be described in three categories; myelinated tracts, nonmyelinated tracts, and cell bodies. In fiber tracts that are eventually myelinated (e.g., tectal SO, cerebellar fiber tracts, and spinal cord white matter), $\mathrm{Ng}$-CAM tended to decrease progressively from a maximum achieved very early in development to a low point in the adult (an average of $17 \%$ of the peak value). In contrast, unmyelinated fibers (e.g., those of the retina) showed a gradual increase in the amount of $\mathrm{Ng}$-CAM at E18, with a gradual decline in the adult (to an average of $64 \%$ of the peak value). In regions composed predominantly of cell bodies (e.g., spinal cord gray matter, cerebellar internal granule cell layer, tectal SGC, and ganglion cell body layer), the levels of $\mathrm{Ng}$-CAM increased, peaked (around 

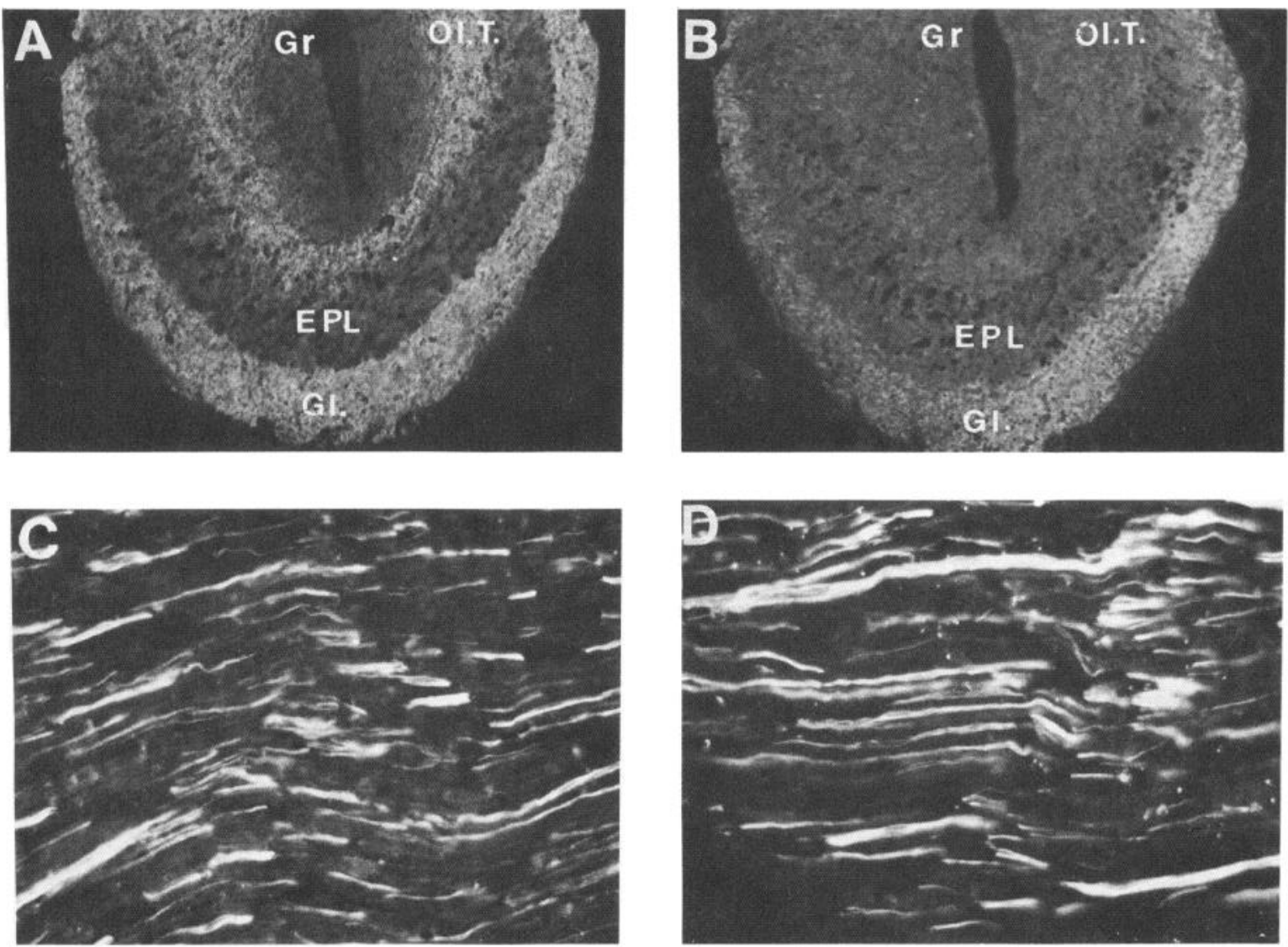

Figure 9. Coronal sections of adult olfactory bulb $(A, B)$ and longitudinal sections of sciatic nerve $(C, D)$. In both regions, patterns that occurred in embryonic tissues were also observed in the adult. $A, \mathrm{Ng}$-CAM was localized to fibers within the peripheral glomeruli $(G l$.) and the olfactory tract $(O l . T$.$) , both of which are not heavily myelinated. The external plexiform layer (E P L)$, which contains mitral and tufted cells, and the granule cell layer $(G r)$ were all unstained. B. The glomeruli were distinguished from the remaining tissue by the increased intensity of staining for N-CAM. $C$ and $D$, Distribution of $\mathrm{Ng}$-CAM $(C)$ and $\mathrm{N}$-CAM $(D)$ indicated identical staining patterns of axons of adult sciatic nerve. With both anti-NgCAM and anti-N-CAM, fibers coursing through the nerve were labeled. $A, B, \times 50 ; C, D, \times 175$.

E18), then declined in the adult (to an average of $49 \%$ of peak values)

For N-CAM, the trend was to decline from initially maximal levels at embryonic times to minimum values in the adult, both on cell bodies (an average of $61 \%$ of peak values) and myelinated tracts of the spinal cord, cerebellum, and tectum (an average of $36 \%$ of peak values). The retina was exceptional; the expression of N-CAM paralleled the expression of $\mathrm{Ng}-\mathrm{CAM}$ in fiber tracts (diminished to $59 \%$ of peak values), but the trends of N-CAM expression followed the trends observed within other developing gray regions.

The quantitative changes of CAMs in white and gray matter are plotted in Figure 10 to illustrate these trends using the spinal cord as an example. The SDs indicate the variability of the photometric quantitation that occurred between labeling experiments. Ratios (Ng-CAM/N-CAM) of the photometric values are presented in Figure 11. Fiber tract layers are compared with cell body regions in the four exemplary regions. The $\mathrm{Ng}$ $\mathrm{CAM} / \mathrm{N}-\mathrm{CAM}$ ratio tended to decrease within developing myelinated tracts. In contrast, this ratio increased within the cell body layers of these regions. These trends suggest that the molecular density of $\mathrm{Ng}$-CAM on the cell surface is indeed high in the regions of neurite formation, but low in the regions of cell clusters. Conversely, the density of N-CAM tends to increase chronologically in regions of cell clusters and unmyelinated fibers.

In each region, the two lines representing $\mathrm{Ng}-\mathrm{CAM}$ to $\mathrm{N}-\mathrm{CAM}$ ratios for tracts and cell bodies crossed one another once during development. The earliest crossing occurred in the retina, followed by spinal cord, then cerebellar and tectal tissues at approximately the same age. This sequence corresponds to the order in which these tissues mature.

\section{Discussion}

Although the approximate times of initial appearances of $\mathrm{Ng}$ CAM during chick embryogenesis (Thiery et al., 1985), as well as the gross distribution of N-CAM in various mammalian and avian brain regions (Chuong and Edelman, 1984), have been surveyed in previous studies, detailed spatiotemporal distributions of the two neuronal CAMs have not previously been mapped. Because such maps are valuable in understanding the relationship between primary processes of neural development and the regulatory influences of cell adhesion in neural histogenesis (Edelman, 1984), the present studies were specifically designed to establish the comparative expression patterns of the two CAMs and to correlate them with events such as cell migration, neurite extension, and myelination.

The results show that striking dynamic changes occur in the patterns of expression of CAMs during neural histogenesis. The main observations are as follows: (1) While N-CAM is ubiquitous in the CNS, Ng-CAM is seen only on postmitotic cell bodies and growing neurites (Thiery et al., 1985); it was not seen on cell bodies after migration or on fibers or tracts that had stopped moving. (2) CAM expression in the CNS and PNS was found to differ as development continued and myelination occurred. In the CNS, Ng-CAM declined as the tracts became 
Table 1. Photometric quantitation of $\mathrm{Ng}-\mathrm{CAM}$ and $\mathrm{N}-\mathrm{CAM}$ immunofluorescence on developing and adult tissues

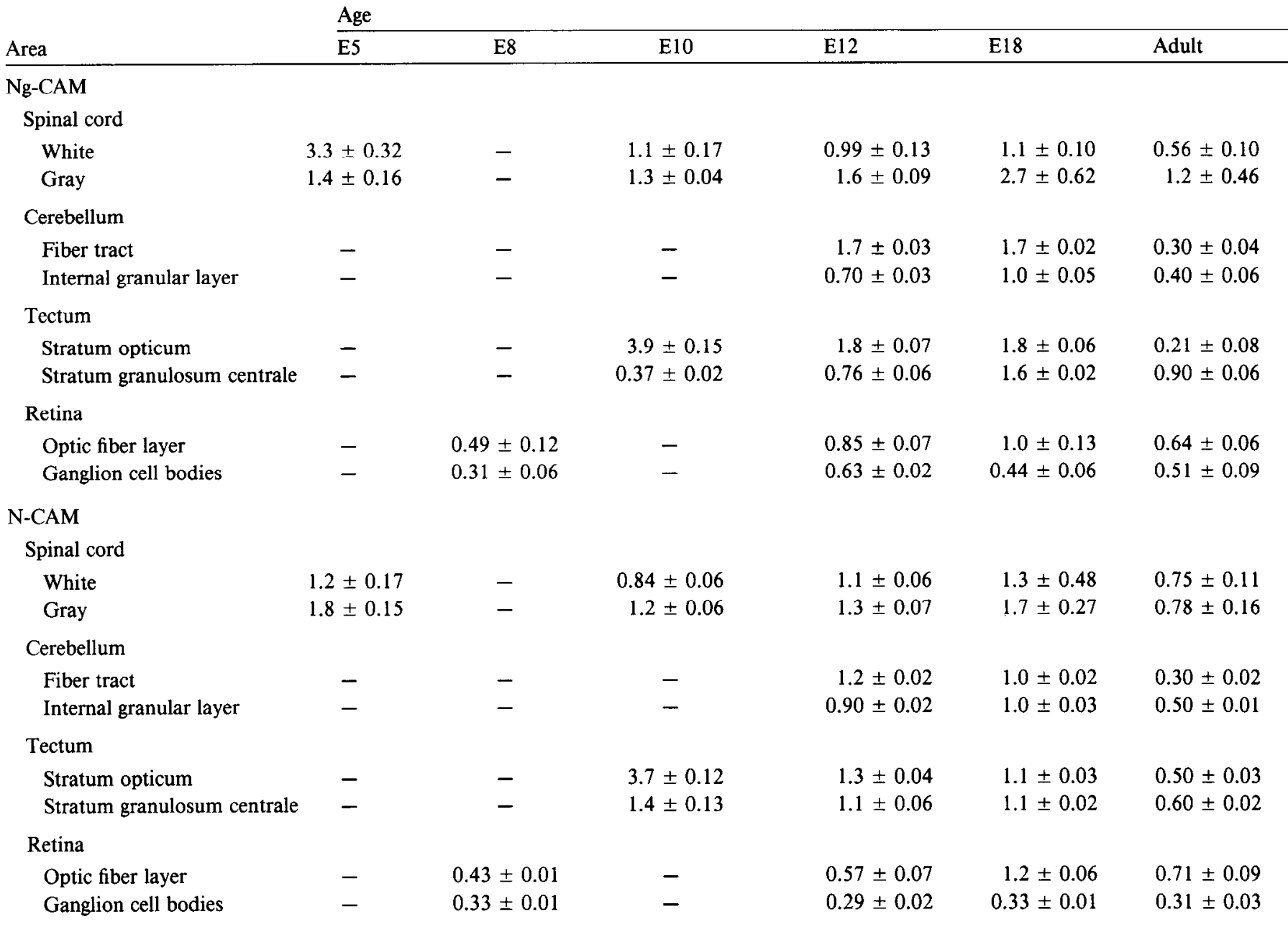

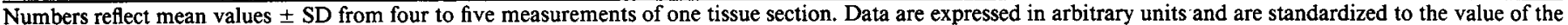
cerebellar granular layer, which was defined as 1 unit.

myelinated, but N-CAM remained constant. Both CAMs persisted on unmyelinated fibers up to adulthood. Within the PNS, the expression of $\mathrm{Ng}-\mathrm{CAM}$ and of $\mathrm{N}-\mathrm{CAM}$ was not noticeably changed during myelination. (3) At all sites of neuron-glia interaction investigated, anti-Ng-CAM antibodies predominantly labeled neurons, although some glia were faintly labeled (also see Grumet et al., 1984a). Ng-CAM was also present on some neurites in the absence of glia, raising the possibility that it may have a role in modulating neurite movement. (4) Even within individual cells, the distribution of the two CAMs underwent dynamic changes. Postmitotic neurons initially expressed only $\mathrm{N}-\mathrm{CAM}$ and expressed $\mathrm{Ng}$-CAM just before migration. In postmigratory neurons, $\mathrm{Ng}$-CAM was present in diminished amounts on the cell body but was strongly expressed on the migrating neurites. Ng-CAM disappeared as myelination by oligodendroglia occurred. In contrast, N-CAM completely covered the cell body and neurites during mitosis, migration, and myelination. The findings suggest that different cellular locations of the two cell adhesion molecules may accompany variable adhesive properties along a single neuronal surface. (5) The overall expression of each of the two CAMs followed a different sequence with different dynamics. The expression of N-CAM occurred earlier in development, was more widespread in distribution, and fluctuated less during development. Expression of $\mathrm{Ng}$-CAM began in the later histogenetic period, was much more localized in particular neural regions, and was transient in some locations. These observations suggest that the differential cxpression of N-CAM and Ng-CAM may produce the widely variant patterns of cell adhesivity that contribute to the organization of nuclei and laminae during neural histogenesis.

\section{Maps and modes of CAM expression}

A set of summary spatial and temporal distribution maps for both CAMs is given in Figure 12. The areas presented exemplify key observations; other areas described in the Results section are not mapped but follow similar principles. The maps show the dynamics of appearance and disappearance of each CAM in diagrams of the anatomic regions as a function of time, as well as a comparison in histologic layers at representative ages.

As shown by the mapped anatomic regions in Figure 12, there are considerable shifts and redistributions of each CAM in all areas as a function of developmental age. The changes in N-CAM are more gradual and occur over smaller ranges as compared with $\mathrm{Ng}$-CAM. The result of these changes is a marked difference between the distribution of N-CAM and Ng-CAM at a characteristic embryonic stage and in the adult stage for a given area (Fig. 12). Ng-CAM shows particularly large degrees of prevalence modulation (Edelman, 1983, 1984) in local regions and over short times, as reflected by its preferential expression in areas undergoing movement. Ng-CAM also shows polarity modulation (Edelman, 1983), in which it is differentially ex- 


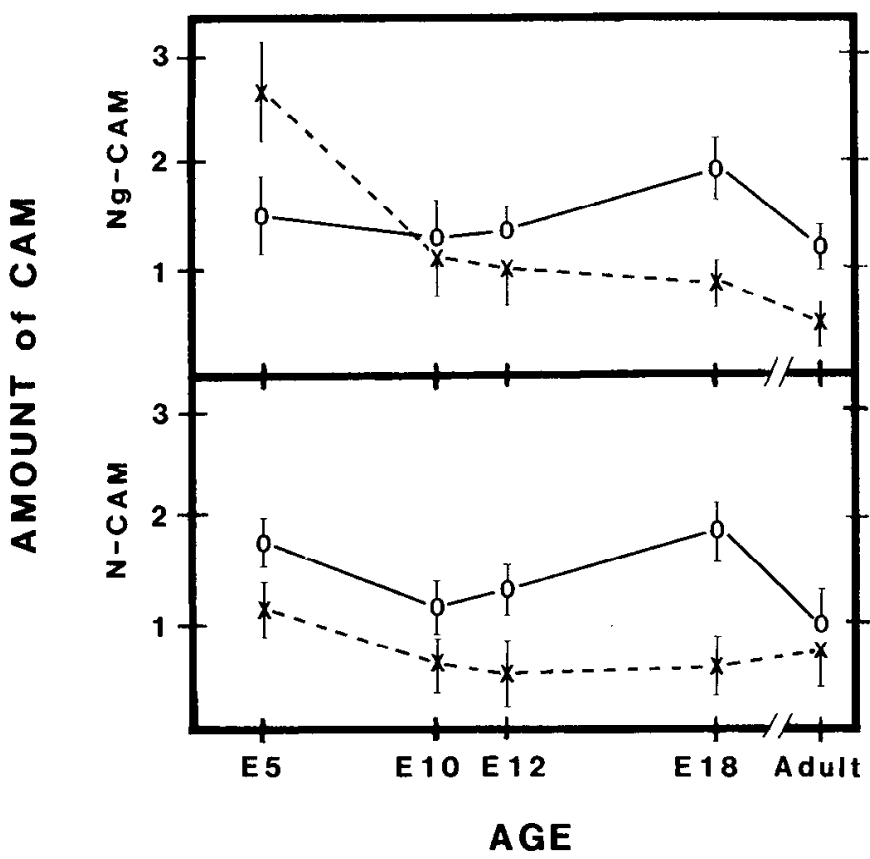

Figure 10. Developmental CAM expression in spinal cord quantitated by photometry. Each data point reflects the mean value of 15 measurements; three spinal cords were processed separately, and five measurements were taken from one tissue section of each. The bars represent SDs. Top, Ng-CAM expression decreased progressively during the development of white matter (crosses and dashed line) but increased in developing gray matter (open circles with solid line). In adult tissues, however, Ng-CAM decreased in both fibers and cell bodies. Bottom, The amount of N-CAM in white matter (dashed line) and gray matter (solid line) fluctuated within a much smaller range. N-CAM increased progressively during development, peaked just prior to birth, then declined in the adult.

pressed on either the soma or its process, depending on whether the cell body is migrating or the neurite is extending.

The complex polarity modulation of CAMs on the cell body and neurites is particularly well demonstrated in adult retinal ganglion cells. Ganglion cell bodies were not labeled for $\mathrm{Ng}$ CAM, but their axons within the retina were labeled. Within the optic nerve proper, however, the same axons were no longer labeled. For N-CAM, E to A conversion occurs much earlier in the retina than the tectum; the relatively more adhesive $A$ form of N-CAM (Hoffman and Edelman, 1983) predominates in the retina, presumably on the cell body, whilc the $E$ form predominates in the tectum (Chuong and Edelman, 1984), presumably on the optic fiber layer (Schlosshauer et al., 1984). Given the differential distribution of $\mathrm{Ng}-\mathrm{CAM}$, and this chemical modulation of N-CAM, the adhesive properties of cell body and neurite are likely to be strikingly different.

It has been suggested that the orderly growth of incoming optic fibers along the tectal surface may be guided by N-CAM positive endfeet on the pial surface (Silver and Rutishauser, 1984). In the present studies we found that the pial surface was faintly stained with anti-N-CAM. Our whole-mount tectal preparations indicated that intrinsic superficial fibers had completely traversed the tectum by E4 and were labeled with anti-N-CAM. This result differs from the observation that the rostral part of the tectum was predominantly labeled with anti-N-CAM antibodies when optic fibers were in contact with N-CAM positive endfeet (Silver and Rutishauser, 1984).

At all periods and in all regions examined, N-CAM was expressed on cell bodies. In the CNS, $\mathrm{Ng}$-CAM was generally absent from cell bodies, except when expressed transiently on migrating cell bodies, such as those in the early gray matter of spinal cord, and in the molecular layer of the cerebellum. These observations suggest that $\mathrm{Ng}-\mathrm{CAM}$ may play a role in mediating cell migration, and they are consistent with perturbation experiments in which the movement of external granule cells in cerebellar explants was inhibited by anti-Ng-CAM antibodies (Grumet et al., 1984b; C. M. Chuong et al., unpublished observations). Whether all neuronal cell bodies pass through a transient phase of $\mathrm{Ng}$-CAM expression is not completely clear because cases in which the expression time is too short may have been missed. Ganglion cell bodies in the retina may be an example of such transient expression. Ependymal cells at all ages are N-CAM positive but Ng-CAM negative. In the PNS, all cell bodies in the peripheral ganglia derived from the neural crest are positive for $\mathrm{Ng}-\mathrm{CAM}$.

In the spinal cord, neurite extension begins when the neuronal cell stops moving (Altman and Bayer, 1984); at this time, NgCAM was localized on neurite processes. In general, the expression of $\mathrm{Ng}$-CAM on processes coincided with the established times at which fiber outgrowth began, and strongly decreased when the tracts were stabilized and myelination occurred. The most dramatic example was seen in the spinal cord, in which $\mathrm{Ng}$-CAM staining was shifted from the presumptive white matter in the embryo to the gray matter in the adult (Fig. 12). This shift occurred at the time when myelination took place in the white matter, and when the unmyelinated collaterals grew into the gray matter. In contrast, N-CAM was found homogeneously on both cell bodies and neurites before and after their migration, and it remained on myelinated fibers.

It is likely that, in addition to being present on extending axons, $\mathrm{Ng}$-CAM was also present on at least some nascent dendrites, particularly in view of the staining found within the IPL of the retina. Other regions that contain dendrites were also stained, e.g., the SGFS of the tectum and the glomerular region of the olfactory bulb. Since optic fibers terminate in the SGFS (DeLong and Coulombre, 1965), the expression of Ng-CAM in this lamina is attributable either to ganglion cell axons, the dendrites within that lamina, or both. Inasmuch as the retinal axons within SO were unstained with $\mathrm{Ng}$-CAM, the staining in SGFS might have been localized on dendrites. Definitive resolution will have to await ultrastructural studies.

In the adult CNS, Ng-CAM remained on nonmyelinated fibers such as olfactory fibers and optic fiber layer of the retina, and was diminished in amount in heavily myelinated tracts like the optic tract and medial longitudinal fasciculus. However, in the adult PNS, $\mathrm{Ng}$-CAM remained on ganglion cell bodies and nerves regardless of the presence of myelin. Thus, the polarity modulation of Ng-CAM is different in the CNS and the PNS (Thiery et al., 1985; and the present study). This may mean that different parts of the nervous system employ different modulation mechanisms for cell adhesion and movement, and it raises the possibility that specific CAMs may function differently in different milieux.

By combining immunohistochemistry with photometry, we have achieved a considerable increase in the resolution of quantitative measurements of CAMs as compared to our previous study (Chuong and Edelman, 1984). The amount of N-CAM in mouse brain regions was found previously to peak shortly after birth and decrease significantly in the adult (Chuong and Edelman, 1984). This same trend can also be observed in the photometric data presented in Table 1 and Figure 10; the immunochemistry used in the present studies also allowed further differentiation of the relative amounts of the CAMs in cell bodies and neurites. In regions rich in cell bodies, the expression of $\mathrm{Ng}$-CAM paralleled that of N-CAM by peaking shortly before birth and decreasing in the adult. In fiber tracts, however, NgCAM was prominent very early in development and diminished to negligible levels during maturation. 
RETINA

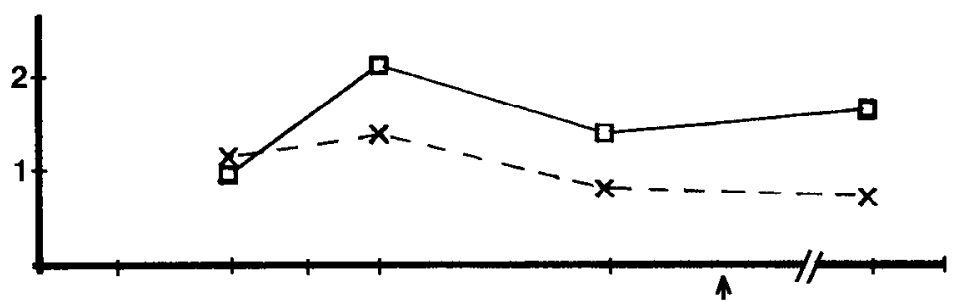

\begin{tabular}{l}
5 \\
8 \\
0 \\
1 \\
2 \\
5 \\
8 \\
0 \\
0 \\
2 \\
$\vdots$ \\
0 \\
0 \\
\hline \\
\hline
\end{tabular}
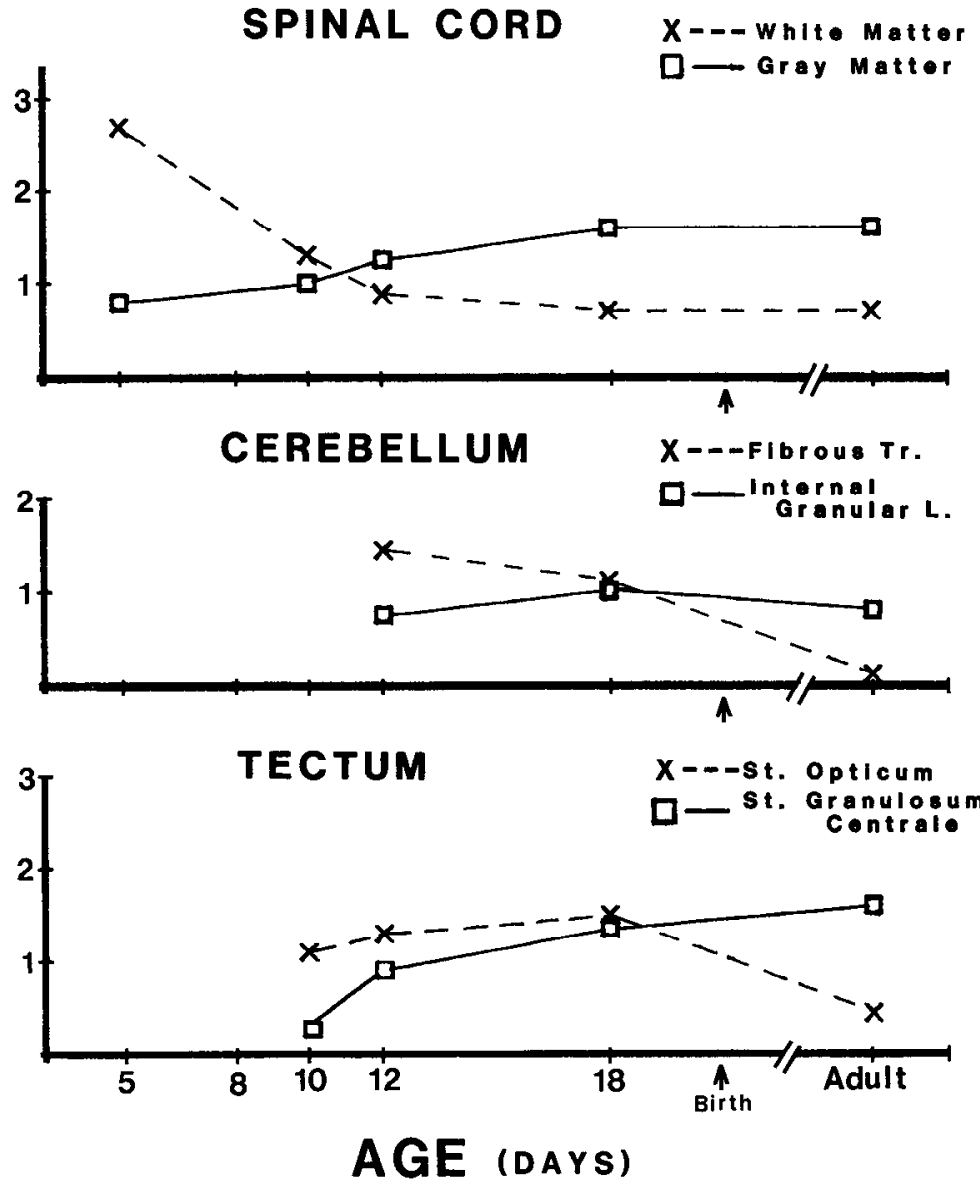

Figure 11. Ratios of $\mathrm{Ng}-\mathrm{CAM}$ to $\mathrm{N}-\mathrm{CAM}$ expression as measured by photometry. Fiber tracts and cell regions are contrasted in four regions: retina, spinal cord, cerebellum, and tectum. In regions of myelinated fibrous tracts, the ratios declined progressively during maturation, and reached their lowest points in the adult after myelination was complete. The amount of $\mathrm{Ng}$ CAM decreased and N-CAM increased (see Table 1). In laminae that contained cell bodies and local unmyelinated neurites, the ratios increased progressively during maturation. The lines representing the ratios crossed in all four of these regions in the order in which they matured; retina is the earliest developing region, and cerebellum and tectum develop later.

\section{Temporal sequences of CAM expression}

N-CAM is a primary CAM that appears in early embryogenesis and is present in various tissues (Edelman, 1983, 1984; Gallin et al., 1983); $\mathrm{Ng-CAM}$ is a secondary CAM that appears much later in development and is restricted to neuroectodermal derivatives (Thiery et al., 1985). The significance of this difference can be seen in the temporal expression sequences listed in Figure 13, which also displays the dynamics of the differential expression of each CAM. The dynamic appearance and disappearance of each CAM presumably reflects changes in cell adhesivity in each tissue. In the perinatal stage, the $\mathrm{E}$ to $\mathrm{A}$ conversion of $\mathrm{N}$-CAM occurs, increasing the rate of homophilic binding (Hoffman and Edelman, 1983) and possibly serving to stabilize neuronal connections (Edelman, 1983; Edelman and Chuong, 1982). Chemical alterations of $\mathrm{Ng}-\mathrm{CAM}$ comparable to $\mathrm{E}$ to $\mathrm{A}$ conversion have not so far been found.

$\mathrm{Ng}$-CAM was also observed in several regions that are sparse in glia. For example, $\mathrm{Ng}$-CAM is seen on the OFL of the adult retina where nerve fibers are apposed to one another, and also on optic nerve fibers before they are myelinated (Rager, 1977).
In addition, in the DRG at E4, cells and their processes were labeled at a time when they are in close proximity to one another (Altman and Bayer, 1984; Hamburger, 1948; Pannese, 1969). These observations suggest that $\mathrm{Ng}$-CAM may have a more general role in modulating cell surface adhesivity during the interactions of neurites than its role in neuron-glial interactions. Consistent with this notion, anti- $\mathrm{Ng}$-CAM antibodies also inhibit adhesion between neurons (Grumet et al., 1984b). Such inhibition does not require that $\mathrm{Ng}$-CAM be a ligand in neuronneuron adhesion; it could affect neuron-neuron adhesion indirectly, e.g., by interacting with N-CAM on the same cell.

Correlation of CAM expression with key developmental events On the basis of its binding functions and anatomical distribution (Grumet et al., 1984a; Thiery et al., 1985), we suggest that NgCAM is central to neuron-glia interactions in the development of the CNS. A number of findings support this view: (1) The initial expression of $\mathrm{Ng}$-CAM occurs at the same time as the astroglial lineage derives from neuroblasts (Thiery et al., 1985). (2) Radial glia are present in the ventral spinal cord in con- 
AGE

\section{REGIONS}

E 5

N-CAM

E 12

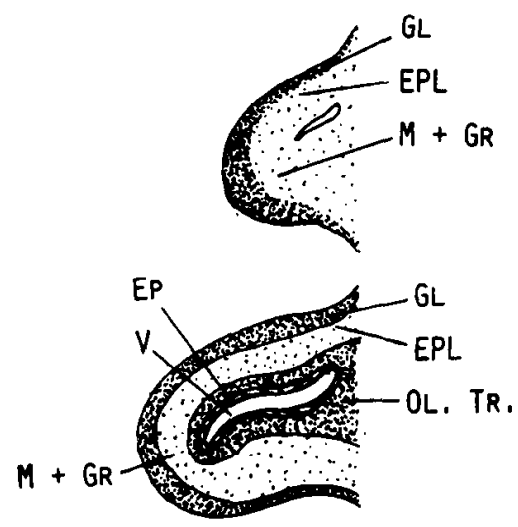

E18
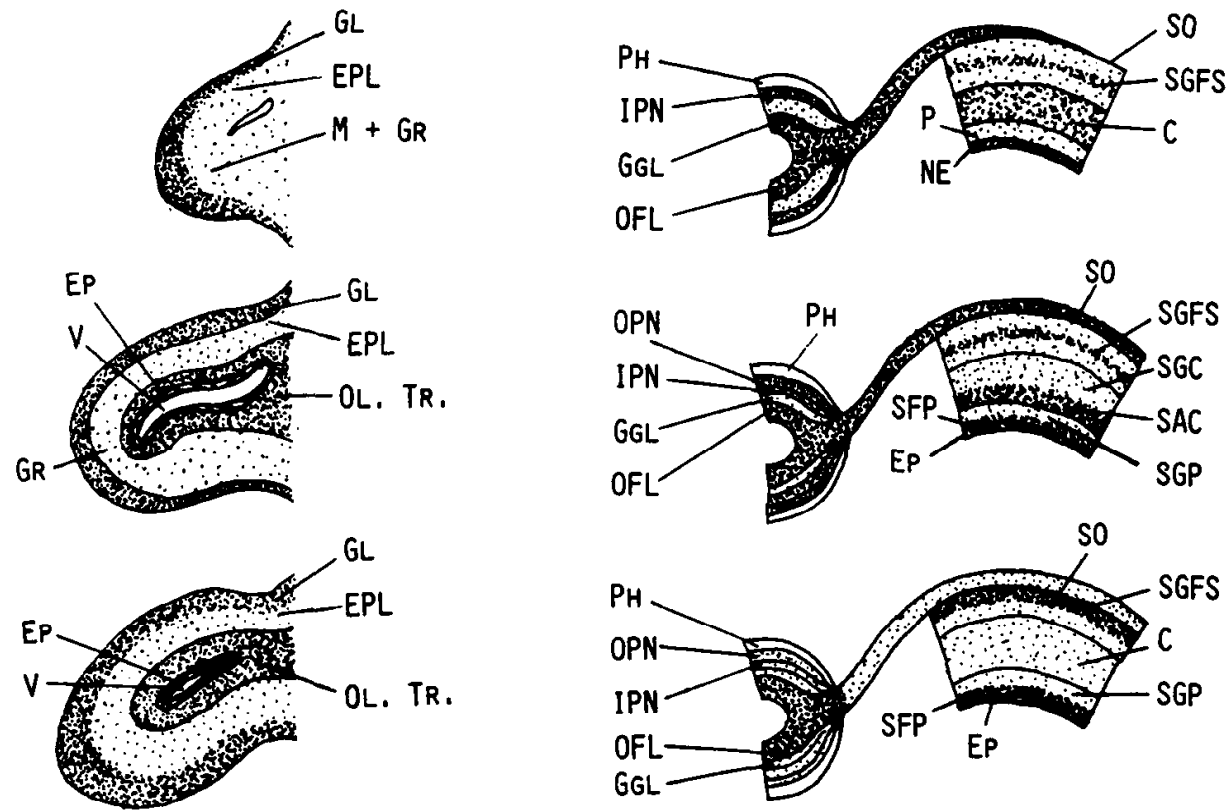

Adult
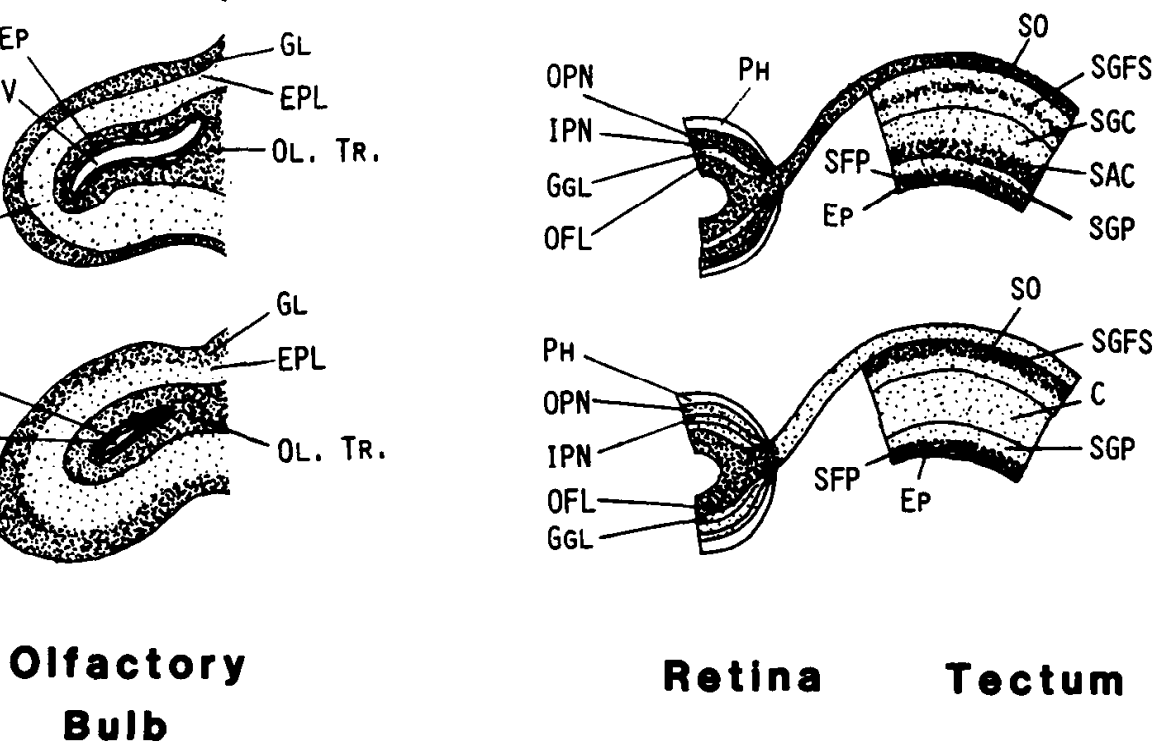

Retina



$\mathbf{N g}$

N

LAYERS

IN

LAMINAE

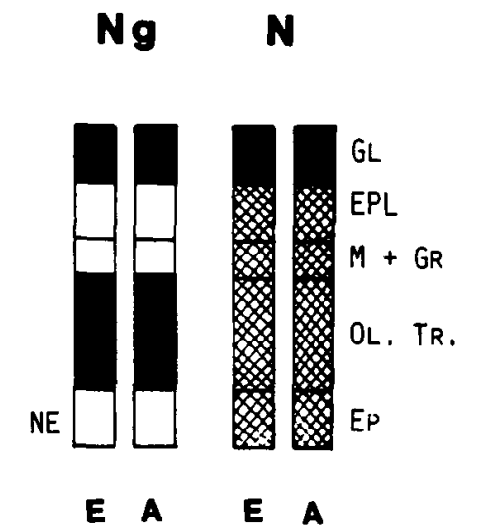

$\mathbf{N g}$

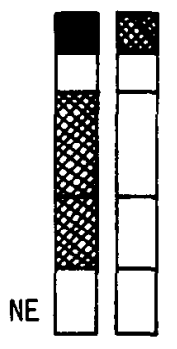

E A
$\mathbf{N}$

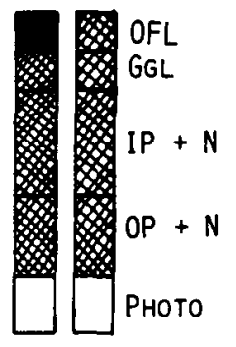

E A
$\mathbf{N g}$

$\mathbf{N}$
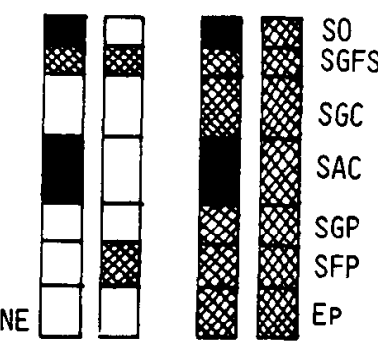

E A

E A

Figure 12. Summary distribution maps of N-CAM and Ng-CAM during development. Schematic drawings, above, show the localization of $\mathrm{N}$-CAM (widely spaced dots) and $\mathrm{Ng}$-CAM (closely spaced dots) in developing and adult brain regions. Since all regions labeled with anti-Ng-CAM were also labeled with anti-N-CAM, the closely spaced dots include both labels. Areas are arranged in a rostrocaudal order: olfactory bulb, retina and tectum, cerebellum, and spinal cord-DRG. The bar graphs, below, summarize the CAM distributions within the various laminae of each region at one representative embryonic time (e.g., E18 for olfactory bulb, retina, tectum, and cerebellum, E8 for spinal cord) and in the adult. The intensity of the fluorescent label is indicated in relative terms as being high (black), moderate (cross-hatching), or negative (white). The distribution of Ng-CAM and N-CAM on the olfactory bulb differed, but neither CAM changed markedly during development. Distinct pattern shifts during development were observed in the retina, tectum, and cerebellum; the most striking shifts occurred in the spinal cord. The staining pattern for 
AGE

REGIONS

E5

E 12

E 18

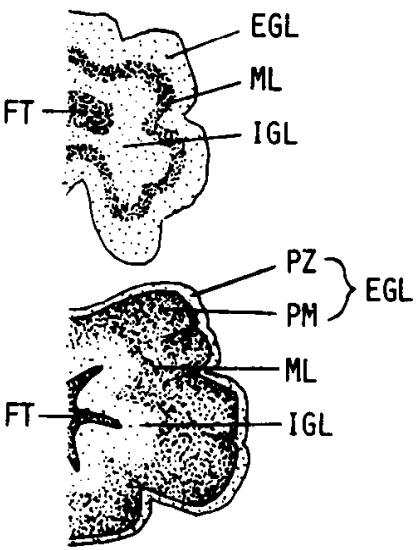

Adult
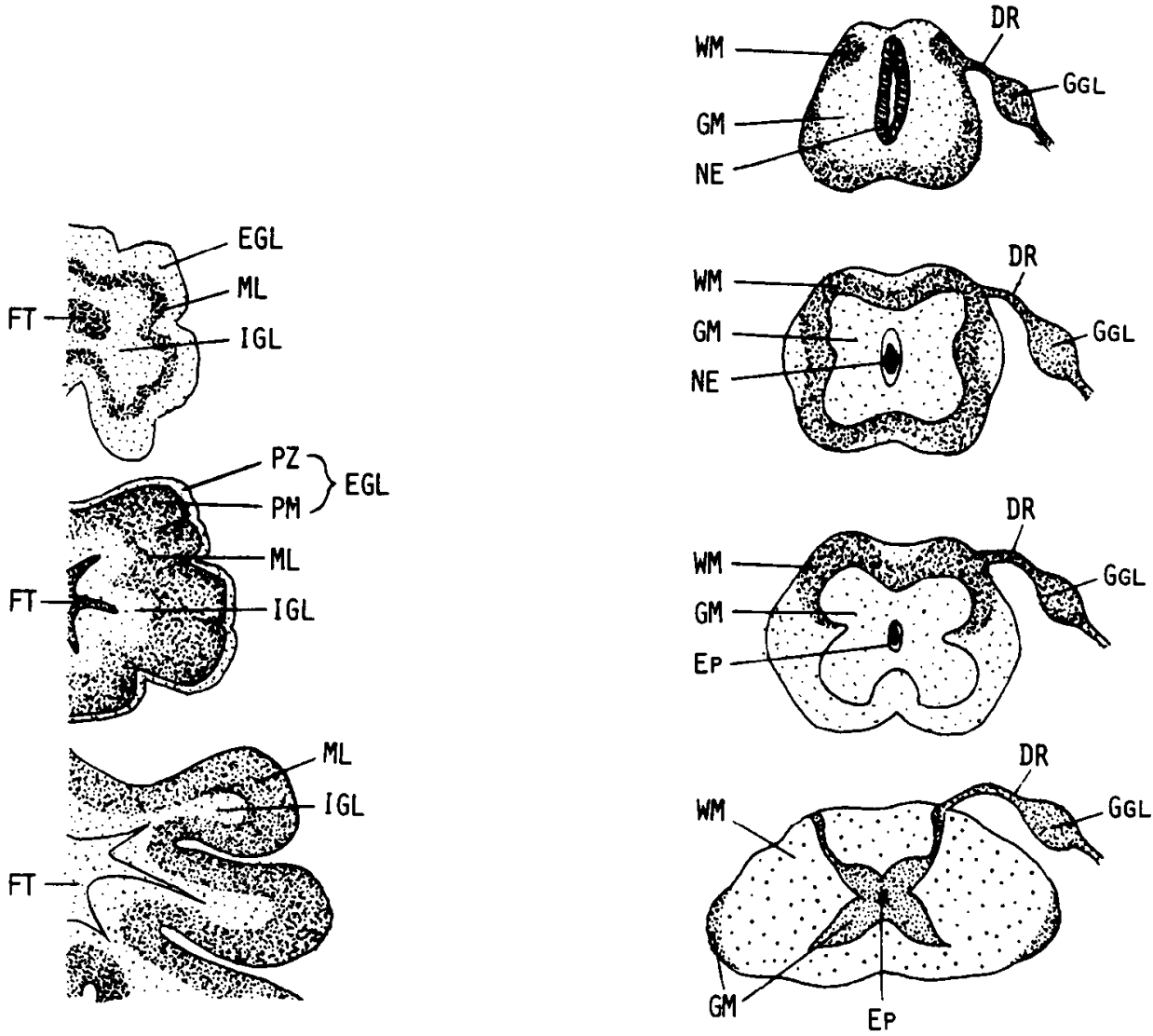

Cerebellum

Spinal

Cord
Dorsal Root

Ganglion
$\mathbf{N g}$
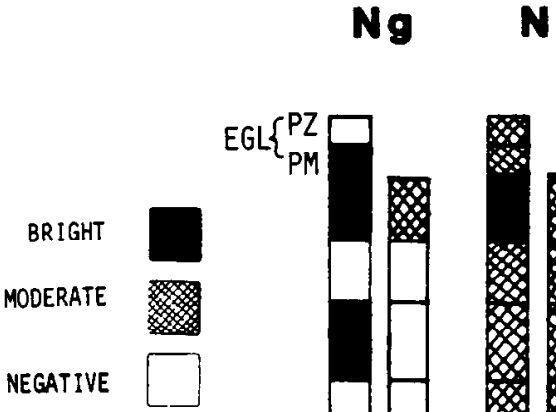

$\mathbf{N g}$
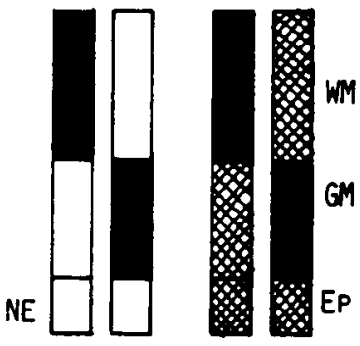

E $\mathbf{A}$

E A
N

$\mathbf{N g}$

$\mathbf{N}$

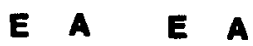

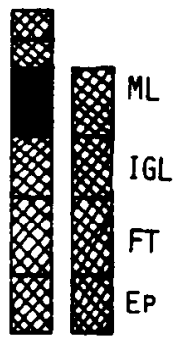

E A

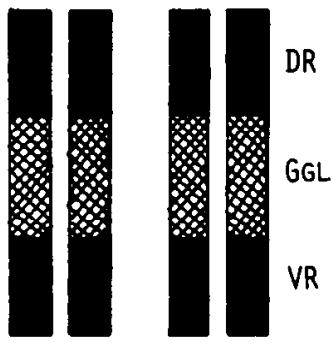

E A E A

both CAMs was the same in developing and adult DRG. Olfactory bulb-Gl, glomerulus; $E P L$, external plexiform layer; $M+G r$, mitral and granule cells; $O l$. $T r$., olfactory tract; $N E$, neuroepithelium; $E p$, ependyma. Retina- $O F L$, optic fiber layer; $G g l$, ganglion cells; $I P+N$, inner plexiform and nuclear layers; $O P+N$, outer plexiform and nuclear layers; Photo, photoreceptors. Tectum-SO, stratum opticum; $S G F S$, stratum griseum et fibrosum superficiale; $S G C$, stratum griseum centrale; $S A C$, stratum album centrale; $S G P$, stratum griseum periventriculare; $S F P$, stratum fibrosum periventriculare. Cerebellum $-E G L$, external granular layer; $P Z$, proliferative zone; $P M$, premigratory zone; $M L$, molecular layer; $I G L$, internal granular layer; $F T$, fibrous tract. Spinal cord $-W M$, white matter; $G M$, gray matter, including the marginal nuclei. DRG-DR, dorsal root; $G g l$, ganglion cell bodies; $V R$, ventral root. 
$N-\operatorname{CAM}\left(1^{\circ}\right)$

\section{STRIATED MUSCLE;}

N-CAM ON STRIATED

MUSCLE CONCENTRATED

AT THE END PLATE;

CARDIAC MUSCLE;

TESTIS

OVIDUCT.

NTODERM
NEURAL DERIVATIVES
NEURAL PLATE;
NEURAL TUBE;
NEURAL CREST
DISAPPEARS FROM
MIGRATING NEURAL
CREST CELLS;
REAPPEARS IN
AGGREGATING
NEURAL CREST

AGE

DAYS STAGE<smiles>[13CH3]C[13CH3]</smiles>

$\operatorname{Ng}-\operatorname{CAM}\left(2^{\circ}\right)$
SPINAL CORD: V, HORN CELL BODIES
AND NEURITES

CILIARY GANGLIA D.R.G. AND FIBERS SYMPATHETIC GANGLIA

TECTUM: SUPERFICIAL FIBERS RETINA: O.F.L SPINAL CORD: D. FUNICULUS, V. FUNICULUS, V. COMMISSURE

TECTUM: S.O., S.A.C.

SPINAL CORD: D. HORN CELL BODIES

MEDIAL LONGITUdinal FASCICULUS

OLFACTORY: $N$, GLOMERULUS, AND TR,

TECTUM: S.F.S., S.F.P.

CEREBELLUM: 'FIBER TR.

Cerebellum: MOLECULAR L.

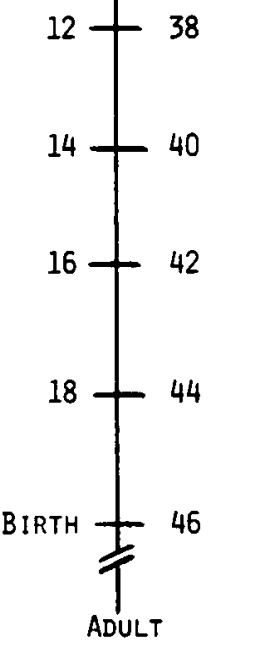

REMAINS ON ALL SUBSEQUENT NERVOUS TISSUES,
CEREBELLUM: MIGRATING GRANULE CELLS

RETINA: I.P.L.

SPINAL CORD: GRAY MATTER

COLLATERALS, D. HORN PATHWAY

DIMINISHES IN SPINAL CORD: WHITE MATTER

DIMINISHES IN CEREBELLUM: FIBER TR, TECTUM: S.O., S.A.C., MEDIAL LONGITUDINAL FASCICULUS

PREVALENT IN SPINAL CORD: GRAY MATTER; RETINA: 0.F.L.; CEREBELLUM: MOLECULAR L.; TECTUM: S.F.P.; OLFACTORY: $N_{1}, T_{1}$, AND GLOMERULUS; D.R.G.; SCiATIC NERVE

Figure 13. Expression scquence of two neuronal CAMs in the developing chick nervous system. N-CAM, a primary cell adhesion molecule, appears early (blastoderm stage) in both neural and non-neural derivatives. After birth, it remains on all subsequent nervous tissues. Ng-CAM, a secondary adhesion molecule, appears later during embryogenesis and is first observed on the developing spinal cord (Thiery et al., 1985). The sequential appearance of Ng-CAM in CNS and PNS regions is summarized. In the adult, Ng-CAM is limited to the unmyelinated CNS regions (tracts or laminae) and PNS. D., dorsal; $E \rightarrow A$, embryonic to adult conversion of N-CAM; I.P.L., inner plexiform layer; $L$. layer; $O . F . L$., optic fiber layer; S.A.C., stratum album centrale; S.F.P., stratum fibrosum periventriculare; S.F.S., stratum fibrosum superficiale; S.O., stratum opticum; $T r$. tract; $V$. , ventral.

junction with the migrating ventral neurons (Altman and Bayer, 1984; Ramon y Cajal, 1960) that were labeled with Ng-CAM. (3) Cerebellar granule cells appear to utilize similar glial elements in their migration (Mugnaini, 1969) and also express high levels of Ng-CAM. (4) The axons composing the ventral com- missure that werc labcled with $\mathrm{Ng}$-CAM are known to follow glial fibers to the contralateral side (Altman and Bayer, 1984). Thus, the in vivo distribution of $\mathrm{Ng}-\mathrm{CAM}$ is consistent with its known function in mediating neuron-glia interactions in vitro (Grumet et al., 1984b). 
The action of oligodendroglia or the presence of myelin in the CNS may alter the expression of $\mathrm{Ng}$-CAM. Myelinated fibers of the white matter of the spinal cord, cerebellum, and optic projections were relatively devoid of Ng-CAM, although minute amounts of $\mathrm{Ng}-\mathrm{CAM}$ were observed at high magnification $(500 \times$; Fig. 3C). In the retinotectal pathway, for example, axons of ganglion cells expressed $\mathrm{Ng}-\mathrm{CAM}$ within the retina, but not within the optic nerve, the chiasm, the tract, or SO-all locations where they are in contact with oligodendroglia (Fig. 7C). The failure to stain with anti-Ng-CAM antibodies was not the result of inaccessibility to the molecule, because the membranes were well stained by N-CAM antibodies. It is tempting to suggest that interactions with oligodendroglia in the CNS may signal the local down-regulation of $\mathrm{Ng}$-CAM expression that might accompany decreased movement and ultimately regulate tract fixation.

Despite its loss in these regions, $\mathrm{Ng}$-CAM persisted in some adult neural tissues, such as the nonmyelinated local circuit fibers of the cerebellar molecular layer, the olfactory bulb, and peripheral nerves. Inasmuch as $\mathrm{Ng}$-CAM expression may be permissive for neurite movement (Grumet et al., 1984b), its continued presence might be linked to regenerative capacities such as those found in the olfactory mucosa (Graziadei and Graziadci, 1977) and in the PNS (Gutman and Young, 1944; Letinsky et al., 1976).

The present analysis of global changes in N-CAM and NgCAM distributions suggests a further relationship between the expression of these two molecules and the occurrence of $E$ to $A$ conversion. The ratio of $\mathrm{Ng}$-CAM to $\mathrm{N}$-CAM decreased progressively within white matter but increased in gray matter. In each region, there was a shift in CAM expression, which resulted in the lines representing the ratios of white and gray matter having crossed. When the regions were graphed in order of earlier to later times of their intersection, the progression paralleled the order of $\mathrm{E}$ to $\mathrm{A}$ conversion in the regions of the mouse CNS (Chuong and Edelman, 1984). Moreover, the crossing point closely followed the time at which cell proliferation ceased, as observed in retina (Rager, 1977), spinal cord (Hamburger, 1948), and cerebellum (Mugnaini, 1969). Further analysis will be required to determine whether these correlations reflect fundamental causative or controlling events.

The differential distributions of Ng-CAM and N-CAM leading to dynamic maps have been interpreted here in terms of the intrinsic functions of each molecule and were correlated with developmental processes such as cell migration, neurite extension, and myelination. The results provide a basic reference both for the design of perturbation experiments and for genetic analyses that should lead to a deeper understanding of the role of cell adhesion in the development of the nervous system.

\section{References}

Altman, J. (1972) Postnatal development of the cerebellar cortex in the rat. I. The external germinal layer and the transitional molecular layer. J. Comp. Neurol. 145: 353-398.

Altman, J., and S. A. Bayer (1984) The development of the rat spinal cord. Adv. Anat. Embryol. Cell Biol. 85: 1-166.

Buskirk, D. R., J.-P. Thiery, U. Rutishauscr, and G. M. Edclman (1980) Antibodies to a neural cell adhesion molecule disrupt histogenesis in cultured chick retina. Nature 285: 488-489.

Chuong, C.-M., and G. M. Edelman (1984) Alterations in neural cell adhesion molecules during development of different regions of the nervous system. J. Neurosci. 4: 2354-2368.

DeLong, G. R., and A. J. Coulombre (1965) Development of the retinotectal topographic projection of the chick embryo. Exp. Neurol. 13: 351-363.

Dubey, P. N., D. K. Kadasne, and V. S. Gosavi (1968) The influence of the peripheral field on the morphogenesis of Hofmann's nucleus major of chick spinal cord. J. Anat. 102: 407-414.

Edelman, G. M. (1983) Cell adhesion molecules. Science 219:450457.
Edelman, G. M. (1984) Modulation of cell adhesion during induction, histogenesis, and perinatal development of the nervous system. Annu. Rev. Neurosci. 7: 339-377.

Edelman, G. M., and C.-M. Chuong (1982) Embryonic to adult conversion of neural cell adhesion molecules in normal and staggerer mice. Proc. Natl. Acad. Sci. USA 79: 7036-7040.

Edclman, G. M., W. J. Gallin, A. Dclouvéc, B. A. Cunningham, and J.-P. Thiery (1983) Early epochal maps of different cell adhesion molecules. Proc. Natl. Acad. Sci. USA 80: 4384-4388.

Fraser, S. E., B. A. Murray, C.-M. Chuong, and G. M. Edelman (1984) Alteration of the retinotectal map in Xenopus by antibodies to neural cell adhesion molecules. Proc. Natl. Acad. Sci. USA 81: 4222-4226.

Gallin, W. J., G. M. Edelman, and B. A. Cunningham (1983) Characterization of L-CAM, a major cell adhesion molecule from embryonic liver cells. Proc. Natl. Acad. Sci. USA 80: 1038-1042.

Goldberg, S. (1974) Studies on the mechanics of development of the visual pathways in the chick embryo. Dev. Biol. 36: 24-43.

Graziadei, P. P. C., and G. M. Graziadei (1977) Continuous nerve cell renewal in the olfactory system. In Handbook of Sensory Physiology, Vol. 9, M. Jacobson, ed., Springer-Verlag, New York.

Grumet, M., and G. M. Edelman (1984) Hetcrotypic binding between neuronal membrane vesicles and glial cells is mediated by a specific cell adhesion molecule. J. Cell Biol. 98: 1746-1756.

Grumet, M., U. Rutishauser, and G. M. Edelman (1982) N-CAM mediates adhesion between embryonic nerve and muscle cells in vitro. Nature 295: 693-695.

Grumet, M., S. Hoffman, and G. M. Edelman (1984a) Two antigenically related cell adhesion molecules of different specificities mediate neuron-neuron and neuron-glial adhesion. Proc. Natl. Acad. Sci. USA 80: $267-271$.

Grumet, M., S. Hoffman, C.-M. Chuong, and G. M. Edelman (1984b) Polypeptide components and binding functions of neuron-glia cell adhesion molecules. Proc. Natl. Acad. Sci. USA 81: 7989-7993.

Gutman, E., and J. Z. Young (1944) The reinnervation of muscle after various periods of atrophy. J. Anat. 78: 15-43.

Hamburger, V. (1948) The mitotic patterns of the spinal cord of the chick embryo and their relation to histogenic processes. J. Comp. Neurol. 88: 221-284.

Hoffman, S., and G. M. Edelman (1983) Kinetics of homophilic binding by embryonic and adult forms of the neural cell adhesion molecule. Proc. Natl. Acad. Sci. USA 80: 5762-5766.

Hoffman, S., B. C. Sorkin, P. C. White, R. Brackenbury, R. Mailhammer, U. Rutishauser, B. A. Cunningham, and G. M. Edelman (1982) Chemical characterization of a neural cell adhesion molecule purified from embryonic brain membranes. J. Biol. Chem. 257: 7720-7729.

Huber, $C_{\text {., }}$ and E. C. Crosby (1933) The reptilian optic tectum. J. Comp. Neurol. 57: 57-163.

Johnson, G. D., and G. N. Araujo (1981) A simple method of reducing the fading of immunofluorescence during microscopy. J. Immunol. Methods 43: 349-350.

Jungherr, E. (1945) Certain nuclear groups in the avian mesencephalon. J. Comp. Neurol. 82: 55-75.

Kuhlenbeck, $H$. (1937) The ontogenetic development of the diencephalic centers in a bird's brain (chick) and comparison with the reptilian and mammalian diencephalon. J. Comp. Neurol. 66: 23-65.

LaVail, J. H., and W. M. Cowan (1971) The development of the chick optic tectum. I. Normal morphology and cytoarchitectonic development. Brain Res. 28: 391-419.

Letinsky, M. S., K. H. Fishbeck, and U. J. McMahan (1976) Precision of reinnervation of original postsynaptic sites in frog muscle after a nerve crush. J. Neurocytol. 5: 691-718.

Mugnaini, E. (1969) Ultrastructural studies on the cerebellar histogenesis. II. Maturation of nerve cell populations and establishment of synaptic connections in the cerebellar cortex of the chick. In $\mathrm{Neu}$ robiology of Cerebellar Evolution and Development, R. Llinás, ed., pp. 749-782, American Medical Association Education and Research Foundation, Chicago.

Pannese, E. (1969) Electron microscopic study on the development of the satellite cell sheath in spinal ganglia. J. Comp. Neurol. 135: 381-422.

Rager, G. (1977) Development of the retinotectal projection in the chicken. Adv. Anat. Embryol. Cell Biol. 63: 1-92.

Rager, G., and U. Rager (1978) Systems-matching by degeneration. I. A quantitative electron microscopic study of the degeneration of retinal ganglion cells in the chicken. Exp. Brain Res. 33: 65-78.

Rager, G., and B. von Oeynhausen (1979) Ingrowth and ramification 
of retinal fibers in the developing optic tectum of the chick embryo. Exp. Brain Res. 35: 213-227.

Rakic, P. (1971) Neuron-glia relationship during granule cell migration in developing cerebellar cortex. A Golgi and electron microscopic study in Macacus rhesus. J. Comp. Neurol. 141: 283-312.

Ramon y Cajal, S. (1960) Studies on Vertebrate Neurogenesis, Thomas, Springfield, IL.

Rothbard, J. B., R. Brackenbury, B. A. Cunningham, and G. M. Edelman (1982) Differences in the carbohydrate structurcs of neural-cell adhesion molecules from adult and embryonic chicken brains. J. Biol. Chem. 257: 11064-11069.

Rutishauser, U., W. E. Gall, and G. M. Edelman (1978) Adhesion among neural cells of the chick embryo. III. Relationship of the surface molecule CAM to cell adhesion and the development of histotypic patterns. J. Cell Biol. 79: 371-381.

Schlosshauer, B., U. Schwarz, and U. Rutishauser (1984) Topological distribution of different forms of neural cell adhesion molecules in the developing chick visual system. Nature 310: 141-143.

Silver, J., and U. Rutishauser (1984) Guidance of optic axons in vivo by a preformed adhesive pathway on neuroepithelial endfeet. Dev. Biol. 106: 485-499.

Thiery, J.-P., J.-L. Duband, U. Rutishauser, and G. M. Edelman (1982) Cell adhesion molecules in early chicken embryogencsis. Proc. Natl. Acad. Sci. USA 79: 6737-6741.
Thiery, J.-P., A. Delouvée, W. J. Gallin, B. A. Cunningham, and G. M. Edelman (1984) Ontogenic expression of cell adhesion molecules: L-CAM is found in epithelia derived from the three primary germ layers. Dev. Biol. 102: 61-78.

Thiery, J.-P., A. Delouvée, M. Grumet, and G. M. Edelman (1985) Initial appearance and regional distribution of the neuron-glia cell adhesion molecule in the chick embryo. J. Cell Biol. 100: 442-456.

Towbin, H. T., T. Staehelin, and J. Gordon (1979) Electrophoretic transfer of proteins from polyacrylamide gels to nitrocellulose sheets: Procedure and some applications. Proc. Natl. Acad. Sci. USA 76: 4350-4354.

Trevino, D. C., R. A. Maunz, R. N. Bryan, and W. D. Willis (1972) Location of cells of origin of the spinothalamic tract in the lumbar enlargement of the cat. Exp. Neurol. 34: 64-77.

Van den Akker, L. M. (1970) An Anatomical Outline of the Spinal Cord of the Pigeon, Royal VanGorum, Assen, The Netherlands.

Williams, P. L., and R. Warwick (1980) Gray's Anatomy, 36th Ed., Saunders, Philadelphia.

Windle, W. F., and M. F. Austin (1935) Neurofibrillar development in the central nervous system of chick embryos up to 5 days' incubation. J. Comp. Neurol. 63: 431-463. 